\title{
The temporal dynamics of resource use by frugivorous birds: a network approach
}

\author{
Jofre Carnicer, ${ }^{1,2,4}$ Pedro Jordano, ${ }^{1}$ and Carlos J. Melián ${ }^{3}$ \\ ${ }^{1}$ Integrative Ecology Group, Estación Biológica de Doñana, Consejo Superior de Investigaciones Cientificas, \\ Isla de La Cartuja, Av. Americo Vespucio s/n Sevilla 41092 Spain \\ ${ }^{2}$ Global Change and Ecophysiology Unit, Center for Ecological Research and Applied Forestry, Edifici C, Campus de Bellaterra, \\ Universitat Autònoma de Barcelona, Cerdanyola del Vallès 08193 Spain \\ ${ }^{3}$ National Center for Ecological Analysis and Synthesis, 735 State St., Santa Barbara, California 93101 USA
}

Abstract. Ecological network patterns are influenced by diverse processes that operate at different temporal rates. Here we analyzed whether the coupled effect of local abundance variation, seasonally phenotypic plastic responses, and species evolutionary adaptations might act in concert to shape network patterns. We studied the temporal variation in three interaction properties of bird species (number of interactions per species, interaction strength, and interaction asymmetry) in a temporal sequence of 28 plant-frugivore interaction networks spanning two years in a Mediterranean shrubland community. Three main hypotheses dealing with the temporal variation of network properties were tested, examining the effects of abundance, switching behavior between alternative food resources, and morphological traits in determining consumer interaction patterns. Our results demonstrate that temporal variation in consumer interaction patterns is explained by short-term variation in resource and bird abundances and seasonal dietary switches between alternative resources (fleshy fruits and insects). Moreover, differences in beak morphology are associated with differences in switching behavior between resources, suggesting an important role of foraging adaptations in determining network patterns. We argue that beak shape adaptations might determine generalist and specialist feeding behaviors and thus the positions of consumer species within the network. Finally, we provide a preliminary framework to interpret phylogenetic signal in plant-animal networks. Indeed, we show that the strength of the phylogenetic signal in networks depends on the relative importance of abundance, behavioral, and morphological variables. We show that these variables strongly differ in their phylogenetic signal. Consequently, we suggest that moderate and significant phylogenetic effects should be commonly observed in networks of species interactions.

Key words: abundance; asymmetry; frugivorous birds; generalist vs. specialist; interaction network; Mediterranean shrubland; morphological traits; phylogeny; resource pulse; switching behavior.

\section{INTRODUCTION}

Ecological communities are complex and dynamic entities, composed of temporally variable populations that interact in very diverse ways (e.g., competition, predation, herbivory, dispersal, pollination, and parasitism, among others), causing continuous changes in the architecture of energy and matter fluxes over space and time. Such overwhelming complexity can be visualized and analyzed by representing communities as networks, in which basically species are represented as nodes and energy fluxes among species are represented as links (Elton 1927, Lindemann 1942, Cohen et al. 1990). Network approaches have a long tradition in ecological research (Pimm 1982, Cohen et al. 1990, Polis and Winemiller 1996) and have provided an appealing way

Manuscript received 27 November 2007; revised 4 November 2008; accepted 5 November 2008. Corresponding Editor: R. Greenberg.

${ }^{4}$ E-mail: jofrecarnicer@ebd.csic.es to visualize and synthesize the structure of ecological interactions (Guimerà and Amaral 2005, Olesen et al. 2007, Clauset et al. 2008, Rooney et al. 2008), to study their emergent properties (Bascompte et al. 2003, Jordano et al. 2003), and to analyze the stability and robustness of communities (May 1973, McCann 2000, Neutel et al. 2007, Rezende et al. 2007, Allesina and Pascual 2008).

However, network approaches have been hampered by the lack of both spatially and temporal explicit analyses (Winemiller 1990). Fortunately, an increasing number of studies are progressively filling these gaps by providing both improved spatially explicit approaches (Holt 2002, McCann et al. 2005, Rooney et al. 2008) and empirically exhaustive descriptions of the temporal dynamics of networks (Winemiller 1990, Neutel et al. 2007, Alarcón et al. 2008, Olesen et al. 2008, OwenSmith and Mills 2008). Similarly, another unsolved challenge is to identify and quantitatively assess the relative importance of the diverse ecological and evolutionary processes that ultimately shape network 
structures (Jordano et al. 2003, Cattin et al. 2004, OwenSmith and Mills 2008, Rooney et al. 2008). Indeed, most ecological networks share some invariant structural properties, but the relative importance of the evolutionary and ecological processes that mold these emergent patterns is usually not well understood. For instance, ecological networks are characterized by a low number of strong interactions and a much greater number of weak interactions (Paine 1992, McCann et al. 1998). Interactions tend to be asymmetric, in both the number of links per species and the strength of the reciprocal effects (Jordano 1987b, Jordano et al. 2003, Vázquez and Aizen 2004, Bascompte et al. 2006). More generally, networks are characterized by having most interactions concentrated in few species that then exert a strong influence on other species (Jordano 1987b, Bascompte et al. 2003). However, despite the importance of the issue, the underlying mechanisms that generate such asymmetric relationships in the number and strength of interactions between species in ecological networks are yet unresolved (Thompson 2005, Jordano et al. 2006, Stang et al. 2006, Bascompte et al. 2007, Vázquez et al. 2007).

Network patterns are the result of a diverse array of ecological and evolutionary processes that operate along a wide range of temporal scales (Johnson and Stinchcombe 2007). On one hand, at short ecological timescales, communities vary in species composition due to processes of birth, death, migration, and dispersal, among others. All these processes cause variation in abundance and composition and might alter the type, number, and strength of interactions observed (Herrera 1984, Jordano 1984, 1985, 1994, Vázquez et al. 2007). Similarly, over short ecological timescales, species might respond to changes in the environmental conditions by phenotypic plastic responses (Agrawal 2001, Price et al. 2003). For instance, consumer species may seasonally switch the resources used, thus modifying the interactions exerted and causing variation in network properties over short timescales (Rooney et al. 2006). On the other hand, at much longer timescales, species evolve or coevolve in a set of morphological and behavioral traits (adaptations) that might determine the species with which they interact (Thompson 2005). Such evolutionary processes may imply the generation of geographical mosaics of selection, coevolutionary hotspots, and traitremixing processes (Thompson 2005, Gomulkiewicz et al. 2007). All these processes may require a considerable number of generations and thus are thought to operate over longer temporal scales (for a review of the temporal convergence of evolutionary and ecological dynamics, see Hairston et al. 2005, Coulson et al. 2006, Fussman et al. 2007, Hendry et al. 2007).

Here we studied the temporal variation in three network properties of consumer frugivorous bird species (number of interactions of bird species $m\left(k_{m}\right)$, interaction strength $\left(\mathrm{IS}_{m}\right)$, and interaction asymmetry $\left.\left(A_{m}\right)\right)$ in a temporal sequence of 28 networks spanning two years. The data set is unique in having robust, independent estimates of resource (fruits, invertebrates) and avian abundances, as well as patterns of resource use based on dietary analyses. The mutualistic plantanimal network analyzed was composed of 24 frugivorous bird species and 15 plant species that produce fleshy fruits. It was located in a Mediterranean shrubland community in southern Spain (Jordano 1984). Three main hypotheses dealing with the temporal variation of consumer interaction properties were tested (Table 1). The three hypotheses examine the effect of bird abundance, bird foraging behavior, and morphology in determining network patterns.

The abundance hypothesis (Jordano 1987b, Vázquez and Aizen 2004, Vázquez et al. 2007) states that shortterm variation in local population abundance is the principal factor that determines the variation in the number and strength of interactions in ecological networks. It predicts that species with greater abundance will have both a greater number of interactions and stronger interactions with other species in the community (Vázquez et al. 2005, 2007, Stang et al. 2006). If the hypothesis holds, we expect that bird interaction properties $\left(k_{m}, \mathrm{IS}_{m}, A_{m}\right)$ would be positively related with the temporal variation of bird abundance $\left(N_{m}\right)$ and/or resource abundance of fruits $\left(R_{1}\right)$ or insects $\left(R_{2}\right)$. If both bird and resource abundance increase the probability of interaction, an increased frequency of interactions should be observed when both birds and resources are very abundant. In this case the interactions between bird density and resource abundances $\left(N_{m} \times R_{1}\right.$ and $N_{m} \times$ $R_{2}$ ) should perform as significant predictors of the temporal variation of network properties $\left(k_{m}, \mathrm{IS}_{m}, A_{m}\right.$; see Table 1).

The switching-behavior hypothesis states that consumer species will show increased number of interactions and higher interaction strengths in the resource channel that they preferentially use during a given elapse of time (Murdoch 1969, Berthold 1976, Van Baalen et al. 2001, Abrams 2006, Rooney et al. 2006, Eveleigh et al. 2007). Resource channels (Rooney et al. 2006, 2008) are composed of two or more sets of species that are usually unrelated at high taxonomic levels (i.e., fungi vs. bacteria, invertebrates vs. fleshy fruits), that show specific turnover rates (production: biomass ratios), and share common top-consumer species. In our study system, top consumers are bird species that seasonally alternate between two resource channels: fleshy fruits $\left(R_{1}\right)$ and invertebrates $\left(R_{2}\right)$ (Jordano 1984, 1985, 1987a). The switching-behavior hypothesis predicts a positive and significant association between the temporal variation in the percentage of fruits used in the diet $\left(\% R_{1}\right)$ and network properties measured $\left(k_{m}, \mathrm{IS}_{m}, A_{m}\right)$.

The species trait hypothesis states that evolutionary processes result in unique morphological, behavioral, and life-history traits that constrain the type, number, and strength of the interactions exerted by species (Thompson 2005, Björklund 2006, Stang et al. 2006). The species trait hypothesis predicts the existence of a 
TABLE 1. Hypotheses and predictions tested.

\begin{tabular}{|c|c|c|c|c|}
\hline Hypothesis & $\begin{array}{l}\text { Independent } \\
\text { variables }\end{array}$ & Theory & Prediction & $\begin{array}{c}\text { Expected } \\
\text { phylogenetic } \\
\text { signal }(K)\end{array}$ \\
\hline $\begin{array}{l}H_{1} \\
\text { Consumer abundance } \\
\text { Resource abundance } \\
\text { Consumer abundance } \\
\text { and resource } \\
\text { abundance }\end{array}$ & $\begin{array}{l}N_{m} \\
R_{1}, R_{2} \\
N_{m} \times R_{1} \\
\quad N_{m} \times R_{2}\end{array}$ & $\begin{array}{l}\text { Differences in local consumer } \\
\text { and resource population } \\
\text { abundance produce } \\
\text { asymmetrical relationships } \\
\text { in plant-animal interactions. }\end{array}$ & $\begin{array}{l}\text { Variation in bird population } \\
\text { abundance, resource } \\
\text { abundance, or their } \\
\text { interaction will } \\
\text { significantly predict bird } \\
\text { interaction properties } \\
\left(k_{m}, \mathrm{IS}_{m}, \text { and } A_{m}\right) .\end{array}$ & nonsignificant or low \\
\hline$\stackrel{\mathrm{H}_{2}}{\text { Switching behavior }}$ & $\% R_{1}, \% R_{2}$ & $\begin{array}{l}\text { Species seasonally switch the } \\
\text { percentage of diet destined } \\
\text { to alternative resource } \\
\text { channels }\left(R_{1} \text {, fruits; } R_{2},\right. \\
\text { invertebrates). Differences } \\
\text { in quantitative use of the } \\
\text { channels shape asymmetrical } \\
\text { relationships in plant-animal } \\
\text { interactions. }\end{array}$ & $\begin{array}{l}\text { Seasonal variation in the } \\
\text { percentage of fruits in the } \\
\text { diet will significantly } \\
\text { predict bird interaction } \\
\text { properties }\left(k_{m}, \mathrm{IS}_{m}, \text { and }\right. \\
\left.A_{m}\right) \text {. }\end{array}$ & mid or high \\
\hline $\begin{array}{l}\mathrm{H}_{3} \\
\quad \text { Species trait }\end{array}$ & $\mathrm{Sp}$ & $\begin{array}{l}\text { Bird species differ in life-history } \\
\text { and morphological traits that } \\
\text { are products of their unique } \\
\text { evolutionary histories. Such } \\
\text { differences between species } \\
\text { determine specific interaction } \\
\text { patterns and produce } \\
\text { asymmetrical relationships. }\end{array}$ & $\begin{array}{l}\text { Interspecific differences in } \\
\text { bird morphological traits } \\
\text { will be associated with } \\
\text { differences between species } \\
\text { in bird interaction } \\
\text { properties }\left(k_{m}, \mathrm{IS}_{m} \text {, and }\right. \\
\left.A_{m}\right) \text { by direct or indirect } \\
\text { causal paths (Fig. 1). Bird } \\
\text { species identity (Sp) will } \\
\text { consistently predict } \\
\text { differences in bird } \\
\text { interaction properties } \\
\left(k_{m}, \mathrm{IS}_{m}, \text { and } A_{m}\right) .\end{array}$ & high \\
\hline
\end{tabular}

Note: Variables are: $N_{m}$, bird abundance for focal bird species $m ; R_{1}$, fruit abundance; $R_{2}$, invertebrate abundance; $\% R_{1}$, percentage of fruits in the diet; $\% R_{2}$, percentage of invertebrates in the diet; $\mathrm{Sp}$, species identity.

limited set of morphological, behavioral, or life-history traits that explain interspecific differences observed between species in the number and strength of interactions (Stang et al. 2006). Similarly, according to the species trait hypothesis, the identity of a species (used as a proxy of its unique evolutionary history) is expected to be a fundamental variable explaining the temporal variation in the type, number, and strength of its interactions with other species. If adaptation strongly determines network patterns, we predict that species would maintain consistently a distinct number and strength of interactions along the whole temporal sequence examined here (two years), irrespective of temporal changes in abundance or species switching behavior. Therefore, we expect that species identity (Sp) will be associated with significantly different values of network properties $\left(k_{m}, \mathrm{IS}_{m}, A_{m}\right)$ along all the temporal sequence (Table 1).

The coupled effect of population abundance variation, switching behavior, and morphological traits might determine to some extent bird interaction patterns (Jordano 1987b, Jordano et al. 2003, Stang et al. 2006, Vázquez et al. 2007). Interestingly enough, abundance, behavioral, and morphological variables are expected to differ in the degree of phylogenetic signal (i.e., to what extent closely related species show similar values for these variables). For instance, local bird abundances have been found to exhibit low or no significant phylogenetic signal (Cofre et al. 2007), and behavioral traits usually exhibit less phylogenetic signal than morphological traits (Wcislo 1989, Blomberg et al. 2003). Thus network properties might rely on a set of variables or specific traits that evolve at different rates and strongly differ in their phylogenetic conservatism (Böhning-Gaese and Oberrath 1999, Blomberg et al. 2003, Cattin et al. 2004, Cofre et al. 2007). In sum, the phylogenetic signal observed in network properties should be quite variable depending on the relative importance of abundance, behavioral, and morphological traits implied (Fig. 1, Table 1). Therefore, phylogenetic signal in networks should be expected to reach intermediate values between those observed for abundance (low or nonsignificant) and morphological traits (high). Overall, our main aim here is to contrast the abundance, the switching behavior, and the species trait hypotheses, to evaluate if these three mechanisms are active and to assess their relative importance.

\section{Material And Methods}

Study site

Fieldwork was conducted in Hato Ratón, an area located at the northeast border of the Doñana National 
Park, Huelva province, southwestern Spain (Jordano 1984). The study period extended from early 1981 through April 1983, encompassing two consecutive fruiting seasons. The study site is a medium to high (2.5-5 m) dense, sclerophyllous shrubland growing on sandy soils at $13 \mathrm{~m}$ of elevation. Vegetation was dominated by tall shrubs and treelets of Pistacia lentiscus (Anacardiaceae), Olea europaea var. sylvestris (Oleaceae), Phillyrea angustifolia (Oleaceae), and Rhamnus lycioides (Rhamnaceae). The shrubland is characterized by abundant cover and diversity of plants producing fleshy fruits (72.2\% cover, $n=21$ species), but is dominated by $P$. lentiscus $(33.4 \%$ cover).

\section{Data}

Quantitative data on interactions between birds and fleshy-fruiting plants were derived from fecal samples of birds captured in mist nets (Jordano 1984, 1985). In total, 10 mist nets were operated weekly, two days per week. The nets were opened from dawn to dusk and checked at hourly intervals. The relative importance of animal prey (mostly arthropods) and vegetable remains (mostly fruits) in bird feces was assessed. The percentage volume occupied by each fraction (to the nearest 10\%) was estimated visually. These measures were used as an estimate of the relative resource-channel use (fruits, $\% R_{1}$; invertebrates, $\% R_{2}$ ). Fecal samples were mostly composed of fruits and invertebrates. Flowers or other resources were very infrequently consumed by a few species and occupy negligible fractions of the samples. Thus, for all the samples, $\% R_{1} \cong 100-\% R_{2}$. Both seeds and pulp remains in the feces were identified, the latter by microscopic inspection of the pericarp tissue. The analyses were carried out from July to November, covering a total of 28 periods of 15 days in 1981-1983. This resulted in a temporal sequence of 28 networks, with 13 and 15 networks per year, respectively. During the spring period (April-June), birds totally switched to an insectivorous diet due to the increased availability of insects and the near absence of fruits in the environment (Carnicer et al. 2008). In spring, fruit-bird interactions were occasional and rare phenomena. For instance, during May-June of 1981, after two months of intensive mist-net sampling, a single fruit-bird interaction was detected. Therefore, we excluded April-June data and restricted the analyses to the months spanning the main fruiting season (July-March).

Networks were examined by grouping by 15-day, monthly, and two-month periods. We observed a high temporal turnover in the type and number of interactions (Appendix A) and a great weekly variation in bird densities, fruit abundances, and percentages of fruits consumed in the diet (Fig. 2). Therefore, we opted for the higher scale of resolution (15 days) in order to more precisely quantify and analyze the temporal variation of interactions within short temporal slices where fluctuations of available resources (fleshy fruits and invertebrates) and consumer densities were minimized.

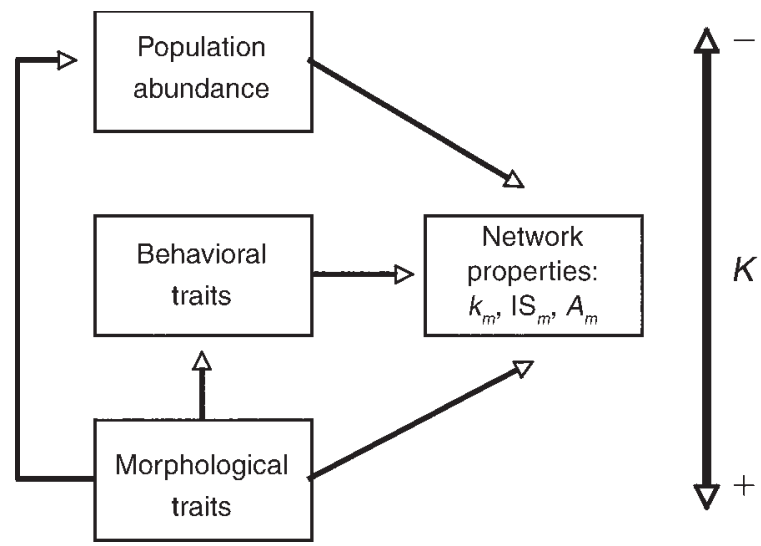

FIG. 1. An illustrative scheme of the hypothesized causal relationships among abundance, behavioral and morphological traits, network properties, and phylogenetic signal (measured by the statistic $K$, which indicates the degree of similarity of closely related species; i.e., the degree of phylogenetic conservatism).

Bird abundance data were obtained by performing weekly counts along a permanent 1-km transect following the procedure of Emlen (1981). Variation in fruit production was estimated using transect counts of the total number of ripe fruits per unit area that were checked every 15 days in 15 replicate plots of $30 \times 1.5 \mathrm{~m}$ (Jordano 1984). Relative variation in invertebrate abundance was calculated using adhesive traps that were set hanging from vegetation and on the ground (Jordano 1984); these traps were monitored weekly. Bird morphological measures (wing, tail, body mass, gape width, tarsus, culmen) were obtained from birds captured in the mist nets using standard procedures (Jordano 1984, 1987a,c). Previous studies of frugivorous Mediterranean birds have documented the relevance of these morphological traits on fruit and insect consumption (Jordano 1987a,c).

The sampling effort applied was constant during the study period, and this allowed the quantitative assessment of the temporal dynamics of interaction networks. However, it is important to bear in mind that two-week temporal slices are not to be interpreted as fully resolved networks: the number of interactions observed is probably limited by the strength of the sampling effort applied (20 mist nets per week; mean $=7.8$ captures per species per time period). Increasing the sampling effort per time unit (e.g., 40 mist nets per week) would surely provide an increase in the number of interactions per time unit detected and a better resolution of the studied networks. The selection of the two-week periods represents a compromise between sample-size returns and the biases that would be introduced by using longer periods of sampling (e.g., monthly or two-month periods).

\section{Network properties measured}

The three hypotheses were examined on three network properties for consumer bird species (the number of 

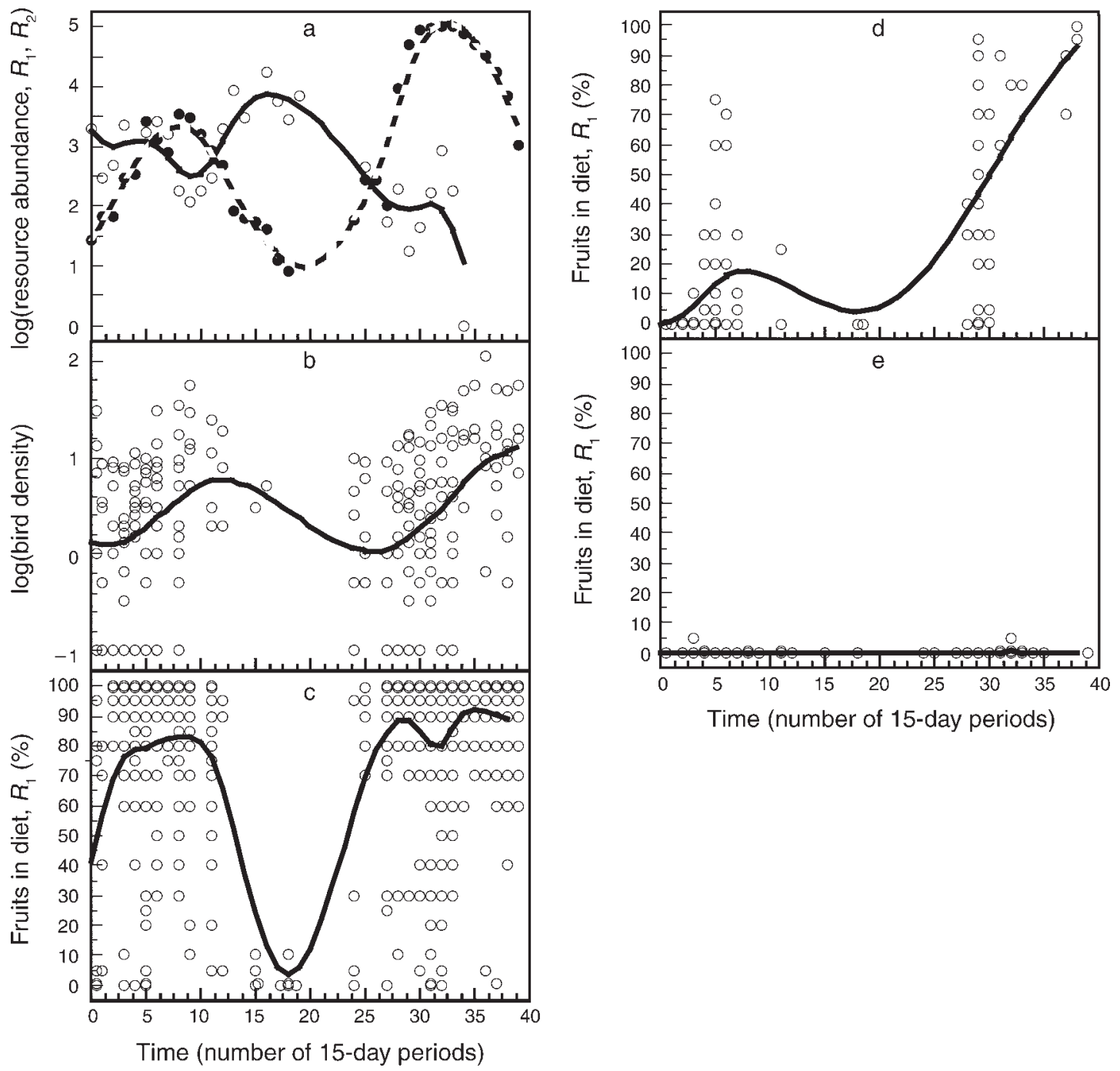

FIG. 2. Temporal trends observed in the studied variables over 40 15-day time periods, from July 1981 to February 1983. (a) Variation in resources, $R$ (log-transformed): fruit abundance (solid circles, $R_{1}$ ) and insect abundance (open circles, $R_{2}$ ). (b) Variation in bird density (log-transformed); within a 15-day period, each circle represents a different species population, but most species were detected in several 15-day periods. The percentage of fruits in the diet is shown for (c) fast switchers, (d) delayed switchers, and (e) invertivore specialists, with circles representing individual samples. Note that data for May-June 1982 were not available, which causes a gap around time period number 20. Lines represent cubic spline fits (JMP version 5); for details, see Methods: Temporal trends in network structure, switching and abundances.

interactions per species or degree, interaction strength, and asymmetry). We restricted our analysis to consumer bird species in the mutualistic plant-animal network (fleshy-fruited plant species and frugivorous birds). This restriction allowed us to focus on hypotheses based on bird natural history. Arthropod-bird interactions were not included in the analyses because the taxonomic resolution of animal prey identification was much lower (i.e., order level) and produced coarse and very imprecise networks. Pajek software was used to calculate species degree and interaction strength for each bird species (De Nooy et al. 2005). Bird species degree $\left(k_{m}\right)$ was defined as the number of interactions of a focal bird species $m$ with other plant species in each time period (see Brandes and Erlebach [2005] for an introduction to the term degree and its use in graph theory). Interaction strength ( IS $_{m n}$, hereafter) was estimated from the total number of fruits recorded for a plant-animal interaction during two weeks (Vázquez et al. 2005, 2007). Interaction strength for a bird species $m$ (IS $m$ ) was calculated as the sum of all the interactions strengths with $n$ interacting plant species $\left(\mathrm{IS}_{m}=\Sigma \mathrm{IS}_{m n}\right.$ ) (Bascompte et al. 2006). Note that this measure of interaction strength does not measure the relative impact of the consumer species on plant demography (Sabo et al. 2005), and thus clearly differs from other system-level measures of interaction strength usually used in microcosm and experimental field approaches (Paine 1992, Sabo et al. 2005). Ideally, 
interaction strength measures also should integrate the fate of seeds once the disperser leaves the mother plant. This would require an evaluation of (1) the treatment the disperser gives to the seeds (digestive tract passage can destroy seeds or enhance germination), (2) the quality of deposition that is associated with spatial movement of dispersers, and (3) the demographic fate of dispersed seeds. However, due to practical reasons, the demographic consequences are only evaluated at the first stage of the dispersal cycle (e.g., the amount of fruit consumed by dispersers during a given time period) and we take this as a proxy for estimating interaction strength (Vázquez et al. 2005, Bascompte et al. 2006).

Following Vázquez and collaborators (2007), we defined interaction asymmetry $\left(A_{m}\right)$ as a species-level property that evaluates the relative difference between the number and strength of interactions exerted by a focal species on its partner species vs. the number and strength of interactions exerted by partner species on the focal species. A detailed mathematical description is provided in Vázquez et al. (2007). Asymmetry values range between -1 and 1 . Positive values indicate that the number and strength of the interactions with partner species are quantitatively more important than the reciprocal effect exerted by the interaction partners on the focal species (Vázquez et al. 2007). Negative values indicate the reverse situation, in which the number and strength of interactions of partner species on the focal species are more important than the effect of focal species on them. Zero values indicate symmetrical interactions (Vázquez et al. 2007). Again, note that this asymmetry measure is not evaluating the demographic effects of fruit consumption on plant populations, and therefore clearly differs from system-level measures that experimentally estimate this effect (Paine 1992).

Asymmetry values along the temporal sequence for each species were calculated using a MATLAB code (see Supplement). Additionally, we measured other network traits: maximum and minimum interaction strength for each species and time period, core, and centrality. A description of these network measures is provided in De Nooy et al. (2005).

\section{Temporal trends in network structure, switching, and abundances}

We studied the temporal variation of three variables: plant-bird interactions, bird switching behavior between invertebrates and fruits, and bird abundance. First, we analyzed fecal samples collected over two years and obtained a temporal sequence of the variation of plantbird interactions. Second, fecal samples were used to assess the proportion of fruits and invertebrates used by each species along the temporal sequence (switching behavior). Differences in switching rates between species were quantified by plotting the percentage of fruits in the diet $\left(R_{1}\right)$ against the resource ratio in the environment (calculated as $R_{1} /\left(R_{1}+R_{2}\right)$; or $\left.R_{1} / R_{2}\right)$ for each species (Carnicer et al. 2008). Sigmoid curves (four-parameter logistic equations) were fitted using nonlinear regression methods. We estimated switching delay for each species by calculating the relative environmental resource ratio at which $25 \%$ of fruits in species' diet was achieved $\left[R_{1} / R_{1}+R_{2}\right]_{25}$. PRISM software version 5.0 (GraphPad Software 2008) was used to interpolate values from the sigmoid curves fitted. In addition to sigmoid fits, we explored and applied linear fits using standard least squares models. These analyses allowed the evaluation of switching-behavior responses in relation to changes in the relative proportion of resources in the environment for each species.

Third, line transect census data were used to estimate the temporal variation in bird abundances independently from the feeding records (derived from fecal analyses) used to characterize interaction patterns. For illustrative purposes, the temporal variation of bird abundance and switching-behavior trends were fitted using the cubic spline method using JMP version 5 (SAS Institute 19892002). This method uses a set of third-degree polynomials spliced together such that the resulting curve is continuous and smooth at the splices (knot points). The estimation is done by minimizing an objective function composed of a combination of the sum of squares error and a penalty for curvature integrated over the curve extent.

\section{Hypothesis testing}

To assess the relative support for each of the hypotheses examined, we modeled bird interaction properties as a function of the variables associated with each hypothesis (Table 1). We used generalized linear mixed models with node identity (Sp), percentage of fruits in the diet $\left(\% R_{1}\right)$, bird abundance $\left(N_{m}\right)$, fruit abundance $\left(R_{1}\right)$, invertebrate abundance $\left(R_{2}\right)$, and the interactions $\left(N_{m} \times R_{1} ; N_{m} \times R_{2}\right)$ as independent variables (Wolfinger and O'Connell 1993). Sampling effort was maintained constant across the whole study period and therefore the number of bird captures in mist nets was proportional to local species' abundance $\left(R^{2}=0.57 ; P<\right.$ 0001). This abundance effect on sample size, and therefore on the number of interactions, was accounted for in the models by introducing the variable density $\left(N_{m}\right)$. However, some species were possibly undersampled because of their idiosyncratic mobility behavior or stochastic sampling effects. To quantitatively account for such deviations, we estimated the sampling effort by regressing for each species the number of captures against the local abundance estimates derived from line transect counts. The residuals of this regression assessed the observed difference between local abundance and the realized sample size for each species and time period and thus provided a reasonable estimate of the sampling effort. Sampling effort, time period (15-day periods), and year were introduced in the models as random variables. We used the GLIMMIX procedure of SAS 9.1.3 (SAS Institute 2008) and JMP 5 to perform the analyses. 
Species with no fruit in the diet were excluded from the analyses.

\section{Testing for the independence of the hypotheses}

The hypotheses examined (abundance, switching behavior, and species trait) are probably not independent. Indeed, life-history and morphological traits are known to affect both bird abundance and resource choice behavior (Böhning-Gaese and Oberrath 1999, 2001, Stang et al. 2006). To assess if morphological traits were effectively associated with bird abundance and interspecific differences in switching behavior (Fig. 1), we applied two different approaches. First, we modeled the percentage of fruits in the diet $\left(\% R_{1 m}\right)$ and abundance $\left(N_{m}\right)$ as a function of nine morphological traits (body mass, wing length, tail length, tarsus length, culmen 1 (length to skull base), culmen 2 (exposed culmen to feather edge), beak width, culmen height, gape width). Specifically, morphological traits were measured in 2028 birds captured in the mist nets during the whole study period. These models allowed us to evaluate if abundance variation and switching behavior were associated with interspecific differences in these morphological traits.

Second, we conducted a path analysis to assess the existence of significant direct and indirect effects of morphological traits on the percentage of fruits in the diet $\left(\% R_{1 m}\right)$, bird abundance $\left(N_{m}\right)$, and bird interaction properties $\left(k_{m}, \mathrm{IS}_{m}, A_{m}\right)$; see Fig. 1. Phylogenetic contrasts were applied to estimate the influence of phylogenetic signal in the path coefficients (Felsenstein 1985, Midford et al. 2002, Martins 2004).

\section{Testing for phylogenetic conservatism in the variables used}

To compare phylogenetic signal of network traits relative to abundance, behavior, and morphological traits, we used the following approaches. To assess the degree of phylogenetic conservatism in bird consumer interaction properties $\left(k_{m}, \mathrm{IS}_{m}, A_{m}\right)$, we applied a randomization test for phylogenetic signal to the variables under study: degree, interaction strength, and asymmetry (Blomberg et al. 2003). The means of the values in $k_{m}, \mathrm{IS}_{m}$, and $A_{m}$ for all the temporal sequence were used for each species. We used the MATLAB program PHYSIG.m to calculate the statistic $K$ (Blomberg et al. 2003). A $K$ value less than one implies that species resemble each other less than expected under Brownian motion evolution along the candidate tree. A $K$ value greater than one implies that close relatives are more similar than expected under Brownian motion evolution, and thus indicates strong phylogenetic conservatism (Blomberg et al. 2003). $K$ values obtained for the dependent variables studied $\left(k_{m}, \mathrm{IS}_{m}, A_{m}\right)$ were compared to those observed for bird abundance $\left(N_{m}\right)$, switching behavior $\left(\% R_{1}\right)$, and nine morphological traits: body mass, wing length, tail length, culmen height, tarsus length, culmen 1 (length to skull base), culmen 2 (length of exposed culmen to feather edge), gape width, and intestine length. These comparisons allowed us to assess the relative phylogenetic conservatism of network traits relative to abundance, behavior, and morphological traits.

\section{REsults}

Temporal trends in abundance, resource switching, and network interactions

The two resource channels (fruits and invertebrates) varied asynchronously with contrasting peaks. Fruits presented a maximum abundance in autumn, whereas the invertebrate abundance maximum was in spring, with a secondary peak in early autumn (Fig. 2). Bird species abundance varied temporally, by the effect of autumn and spring migratory passes, migration of wintering and breeding species, and variation in local resident abundance. Overall, bird abundances were greater in autumn and winter, matching the temporal pattern of fruit abundance (Fig. 2).

The bulk of the species showed seasonal shifts in the percentage of fruits $\left(\% R_{1}\right)$ and invertebrates $\left(\% R_{2}\right)$ in the diet. Switching behavior was observed in 14 out of 24 species. We could differentiate three basic types of switching behavior: fast switchers, delayed switchers, and invertebrate specialists (Figs. 2 and 3, Appendix B). Fast switchers were species that very rapidly increased the percentage of fruits in the diet with relatively small increases in the ratio of fruits to invertebrates in the environment. Delayed switchers demanded a greater increase in the ratio of fruits to invertebrates to start switching to the fruit resource channel (Fig. 3). When they finally switched, they switched to a lesser extent, thus conserving a relatively high percentage of invertebrates in the diet. Invertebrate specialists were those species that were insensible to the changes in the environmental ratio of fruits to invertebrates and maintained consistently an invertivorous diet coupled with the occasional ingestion of some fruits. Out of 20 species, 10 behaved as fast switchers (Erithacus rubecula, Phoenicurus phoenicurus, Sylvia atricapilla, S. borin, S. cantillans, S. communis, S. hortensis, S. melanocephala, Turdus merula, T. philomelos), four species behaved as slow switchers (Luscinia megarhynchos, S. undata, Muscicapa striata, Ficedula hypoleuca), and five as invertivore specialists (Hippolais polyglotta, Phylloscopus collybita, P. bonelli, P. trochilus, Regulus ignicapillus). Finally, for six species, interaction data were too scarce to evaluate any temporal trend in resourcechannel use (Parus caeruleus, P. major, P. cristatus, Phoenicurus ochruros, Saxicola torquata, Turdus iliacus). When analyzing the variation in the percentage of fruits in the diet as a function of the relative resource supply (calculated as $R_{1} /\left(R_{1}+R_{2}\right)$ or $\left.R_{1} / R_{2}\right)$, significant fits were obtained applying both sigmoid nonlinear fits and linear least square models. Responses of fast switchers (the most numerous group) consisted of an initial linear response that accounted for the bulk of the variation 


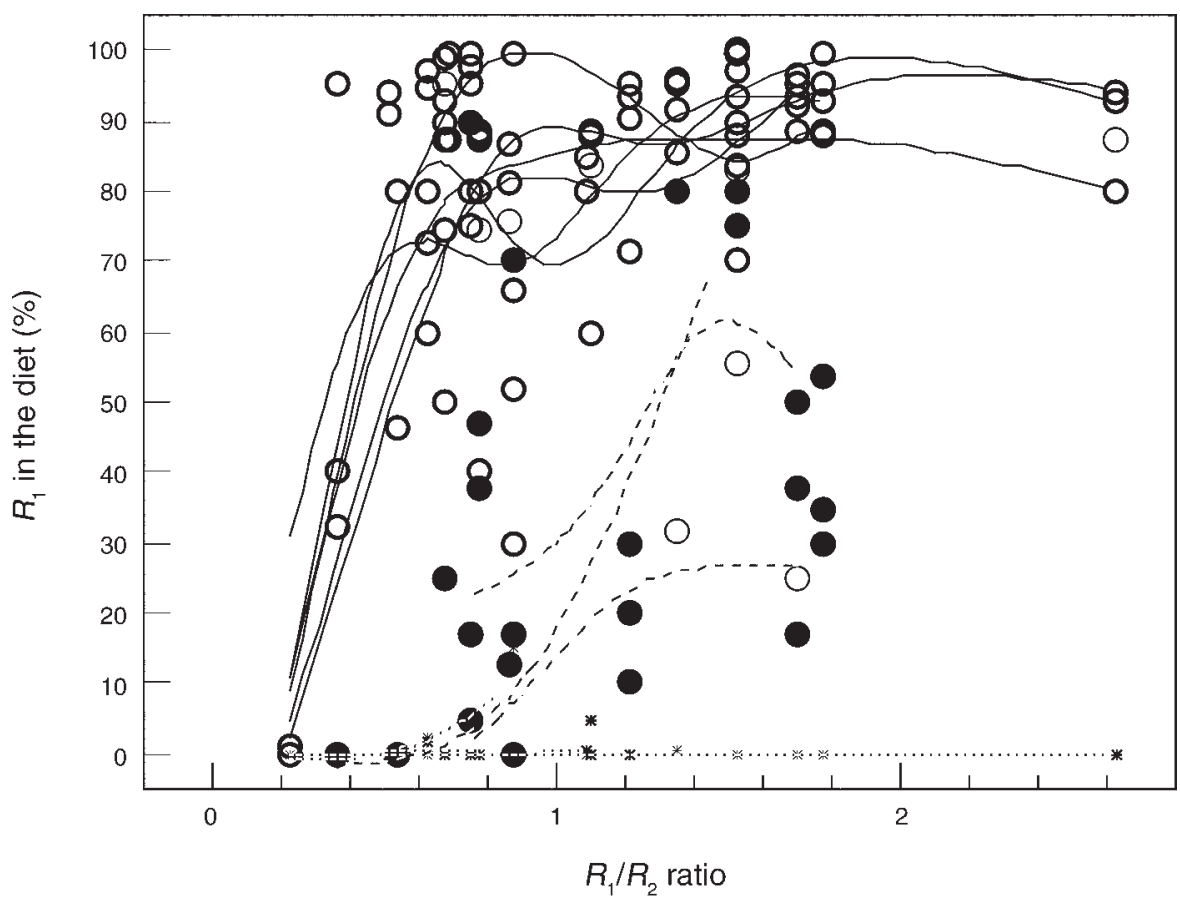

FIG. 3. Bird switching-behavior trends observed between fruit resources $\left(R_{1}\right)$ and invertebrate resources $\left(R_{2}\right)$. The figure distinguishes between fast switchers (open circles, solid lines), slow switchers (solid circles, dashed lines), and invertebrate specialists (asterisks, dotted lines).

and a subsequent saturation phase (at $80-100 \%$ of fruits in the diet) in which the percentage of fruits was independent of the relative quantity of fruits in the environment (Fig. 3, Appendix B).

The temporal structure of plant-bird interactions is shown in Appendix C (see Nagy 1987). The total number of interactions was higher during the fruit peak periods (September-November), matching the trends in fruit resource variation and bird abundance (Fig. 2).

\section{Hypothesis testing}

The three hypotheses examined were empirically supported (Table 2). However, a different pattern of response was observed for species degree and interaction strength. Abundance was a good predictor for interaction strength patterns, but explained less variation in qualitative network patterns (degree) (Table 2, Fig. 4). The interaction between resource and bird abundance was strongly significant for degree, indicating that both consumer and resource abundances contribute to increase the probability of interaction. The models explained $62-76 \%$ of variation across species in network properties (Table 2).

\section{Testing for hypotheses independence}

Models explaining the variation of bird abundances $\left(N_{m}\right)$ and the percentage of fruits in the $\operatorname{diet}\left(\% R_{1}\right)$ using morphological traits performed much better in the case of the percentage of fruits in the diet than with abundance (Appendix D). Indeed, morphological traits explained only $6 \%$ of the variation in bird abundances $(P<0.05)$ but explained $43 \%$ of variation among species

TABLE 2. Effect tests for the independent variables.

\begin{tabular}{|c|c|c|c|c|c|c|c|c|c|}
\hline \multirow[b]{2}{*}{ Test effect } & \multicolumn{3}{|c|}{$k_{m}, R^{2}=0.69$} & \multicolumn{3}{|c|}{$\mathrm{IS}_{m}, R^{2}=0.62$} & \multicolumn{3}{|c|}{$A_{m}, R^{2}=0.76$} \\
\hline & $\mathrm{SS}$ & $F$ & $P$ & SS & $F$ & $P$ & SS & $F$ & $P$ \\
\hline $\mathrm{Sp}$ & 128.13 & 3.76 & $<0.0001$ & 46019.6 & 4.32 & $<0.0001$ & 4.803 & 3.210 & $<0.0002$ \\
\hline$\% R_{1}$ & 8.80 & 4.40 & 0.039 & 889.6 & 1.42 & 0.236 & 0.770 & 8.750 & 0.004 \\
\hline$N_{m}$ & 18.34 & 9.16 & 0.003 & 16628.8 & 26.56 & $<0.0001$ & 0.524 & 5.959 & 0.017 \\
\hline$R_{1}$ & 3.48 & 1.74 & 0.191 & 2545.8 & 4.07 & 0.047 & 0.168 & 1.912 & 0.171 \\
\hline$R_{2}$ & 1.28 & 0.63 & 0.426 & 1023.3 & 1.63 & 0.205 & 0.024 & 0.274 & 0.602 \\
\hline$N_{m} \times R_{1}$ & 17.89 & 8.93 & 0.004 & 757.7 & 1.21 & 0.27 & 0.048 & 0.544 & 0.463 \\
\hline$N_{m} \times R_{2}$ & 15.01 & 7.50 & 0.008 & 5100.2 & 8.14 & 0.006 & 0.037 & 0.420 & 0.519 \\
\hline Sampling effort & 7.31 & 3.65 & 0.060 & 3956.9 & 6.32 & 0.014 & 0.071 & 0.808 & 0.371 \\
\hline
\end{tabular}

Notes: Dependent variables are the number of interactions or degree $\left(k_{m}\right)$, interaction strength $\left(\operatorname{IS}_{m}\right)$, and asymmetry $\left(A_{m}\right)$ for focal bird species $m$. The total percentage of variance explained $\left(R^{2}\right.$ adjusted, $\left.P<0.0001\right)$ is also provided for the three models $\left(k_{m}\right.$, $\left.\mathrm{IS}_{m}, A_{m}\right)$. 
a

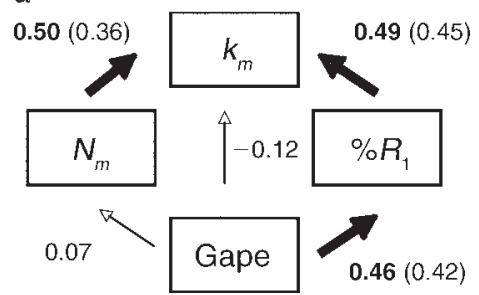

b

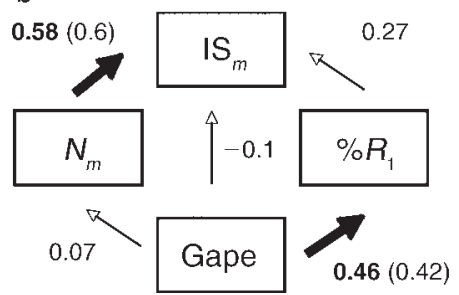

C

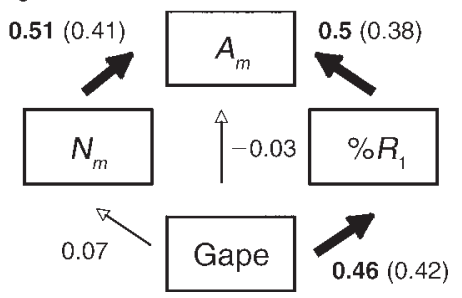

FIG. 4. Path diagram of expected causal effects of gape width, bird population density $\left(N_{m}\right)$, and switching behavior $\left(\% R_{1}\right)$ on three network properties: (a) degree $\left(k_{m}\right)$; (b) interaction strength (IS $)_{m}$ ); and (c) asymmetry $\left(A_{m}\right)$ for focal bird species $m$. Heavy arrows and boldface values represent significant path coefficients $(P<0.05)$. Values within parentheses are path coefficients corrected by phylogenetic contrasts.

in the percentage of fruits in the $\operatorname{diet}(P<0.0001)$. Beak morphology traits (gape width and culmen length) were strongly associated with the percentage of fruits in the diet (Appendix D). In line with these results, path analyses indicated significant indirect effects of gape width on the number and asymmetry of bird interactions $\left(k_{m}, A_{m}\right)$ through their effect on switching behavior $\left(\% R_{1}\right)$ (Fig. 4). Overall, our results suggest that foraging morphological traits are directly associated with switching behavior, gape width being the character most strongly associated with this behavior.

\section{Testing for phylogenetic signal}

The three bird interaction properties examined $\left(k_{m}\right.$, $\left.\mathrm{IS}_{m}, A_{m}\right)$ showed a significant phylogenetic signal $(P<$ 0.05; Appendix E). In contrast, other network measures (centrality and minimum interaction strength) did not show a significant phylogenetic effect. As expected, morphological traits were characterized by stronger phylogenetic signals and abundance was not significantly associated with phylogeny. Interestingly enough, we found intermediate $K$ values for all network properties examined. Indeed, network $K$ values were weaker than $K$ values for morphological traits, similar to $K$ values observed for behavioral traits and greater than $K$ values observed for species abundance (Fig. 5).

\section{DisCuSSION}

Our results suggest that network patterns are influenced by a diverse array of ecological processes that may operate at different temporal timescales (Hastings 2004). The coupled effect of local abundance variation, phenotypically plastic responses (resource choice and switching behavior) to the varying food supply, and species evolutionary adaptive processes might be shaping network patterns. We showed that both species abundance and switching behavior vary at the ecological timescale and determine bird interaction patterns. Our results also supported the existence of adaptations in ecomorphological and foraging traits that shape the architecture of network patterns (Stang et al. 2006). However, the importance of morphological constraints differed in the case of species abundance and switching behavior hypotheses. Morphological traits were weakly related to interspecific differences in bird abundance but strongly related to the percentage of fruits in the diet and the ability to seasonally switch among invertebrates and fruits as their supply varies. Thus, switching behavior changes seasonally at an ecological timescale but critically depends on foraging morphological traits (beak shape) that might evolve at much slower temporal rates. These findings are consistent with the existing literature that suggests an important role of bird beak shape in constraining the type and number of interactions established by birds (Jordano 1987a, b, Benkman 1999, Böhning-Gaese et al. 2003); promoting diet diversification and speciation processes (Abzhanov et al. 2004, Wu et al. 2004, Fitzpatrick et al. 2005, Grant and Grant 2006, Phillimore et al. 2006) and even highlighting a

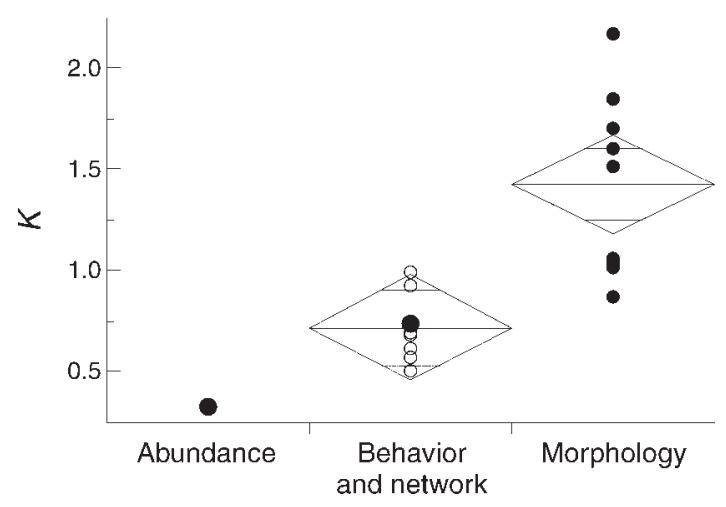

FIG. 5. Comparison of the values of the statistic $K$ in network properties (open circles: degree, interaction strength, asymmetry, maximum interaction strength, minimum interaction strength, centrality, and core) and $K$ values for abundance, behavioral, and morphological traits (solid circles: $N_{m}, \% R_{1}$, gape width, body mass, intestine length, culmen height, wing length, tail length, tarsus length, and culmen length). A $K$ value less than 1 implies that species resemble each other less than expected under Brownian motion evolution along the candidate tree; a $K$ value greater than 1 implies that close relatives are more similar than expected under Brownian motion evolution. A Tukey-Kramer test comparing the mean phylogenetic signal in network properties vs. morphological traits shows significance $(P<0.0001)$. The line across the center of each diamond represents the group mean. The vertical span of each diamond represents the 95\% confidence interval for each group. Short horizontal lines near the top and bottom of each diamond are overlap marks at $(\sqrt{2} / 2) \mathrm{CI}$ above and below the group mean. 
possible role of beak shape in driving the evolution of bird behavior (Podos 2001).

Our results provide a preliminary framework to interpret consumer specialization and generalization patterns in bird-fleshy fruiting plants networks in terms of temporal responses to the resource supply. First, three main types of specialization-generalization behaviors were found in birds: fast switchers (generalists), delayed switchers (circumstantial generalists), and invertebrate specialists. Only fast switchers play a significant role in shaping the architecture of plant-bird network in terms of degree and interaction strength because they become central in the network, i.e., concentrate a high number of interactions. Thus, bird species characterized by a low number of plant-bird interactions and weak interaction strengths were invertebrate eaters that only fed on fruits when they were extremely abundant (delayed switchers) or invertebrate eaters that only occasionally consumed fruits (invertebrate specialists). Interestingly enough, these findings are consistent with the predictions of optimal foraging theory. Theory predicts that species with higher handling times (smaller gape widths) would only use the less profitable prey (fruits) when the rate of encounter with the more profitable prey (insects) falls below a critical value (i.e., when fruits are very abundant and insects are scarce) (Berthold 1976, Charnov 1976, Stephens and Krebs 1986, Fryxell and Lundberg 1994, Krivan 1996, Berec et al. 2003). Thus, switching in insectivore species should be more prone to occur in the autumn fruiting peak, when fruits are superabundant and invertebrates scarce. This is consistent with the trends described for delayed-switching species. We suggest that optimal foraging and switching behavior theory might be applied to understand and predict bird specialization-generalization network patterns (Fryxell and Lundberg 1994, Krivan 1996, van Baalen et al. 2001, Abrams 2006, Beckerman et al. 2006), especially situations in which alternative food resources vary seasonally.

The patterns shown highlight that bird interaction strength patterns are strongly associated with abundance variation. The interaction of resource and consumer abundance was highly significant, suggesting that the coupled phenomena of high consumer and resource abundances increase the probability of interaction. Different multi-scale spatial resource-tracking responses are probably shaping local bird abundances and plant-animal interaction patterns in southern Spain (Rey 1995, García and Ortiz-Pulido 2004, Tellería et al. 2008). For instance, Tellería et al. (2008) have recently found strong interspecific differences in spatial resourcetracking responses among frugivorous birds, with significant spatial correlations between resource and bird abundances in some species ( $S$. atricapilla, $E$. rubecula) and the absence of a significant correlation in others (S. melanocephala, T. merula, T. philomelos). Our results are consistent with their empirical findings, and we observed positive significant temporal correlations between fruit availability and bird abundances only in $E$. rubecula $\left(R^{2}=0.17, P<0.04\right)$ and $S$. atricapilla $\left(R^{2}=\right.$ $0.33, P<0.002)$.

Abundance was weakly related to the variation in morphological traits and no phylogenetic signal was observed in bird abundance. This evidence implies that interaction strength patterns of frugivorous birds might be less influenced by evolutionary constraints. This assertion is strongly supported by recent findings of Rezende et al. (2007), who reviewed 36 plant-pollinator and 23 plant-frugivore mutualistic networks and found that the amount of phylogenetic signal for interaction strength was significantly lower than for estimates of species degree. We suggest that switching behavior and morphological constraints play a greater role in determining the type and number of interactions exerted by bird species, whereas abundance variation plays a more active role in determining bird interaction strength patterns.

Obviously, other complementary processes might be influencing the interaction patterns but are not examined here. Likely candidates would be geographic variation and scale dependence in the patterns of foraging (Tellería and Carbonell 1999, García and Ortiz-Pulido 2004, Tellería et al. 2008), spatially aggregative foraging behaviors (Jordano 1985, Rey 1995, Tellería et al. 2008, Yang et al. 2008), reproductive responses to resource pulses (Yang et al. 2008), and conspecific and heterospecific attraction among birds (Mönkkönen and Forsman 2002).

Our results also provide some new insights into the question of what determines the strength of phylogenetic signal in network patterns. We showed that bird interaction properties depend on species abundance, behavioral, and morphological traits. All these types of properties strongly differ in their phylogenetic conservatism (Blomberg at al. 2003). Therefore, the strength of phylogenetic signal observed in network patterns might be explained by the relative importance of abundance, behavioral, and morphological variables and should usually take intermediate $K$ values. Accordingly, we should expect that interaction strength patterns would be characterized by weaker phylogenetic signals because they are more influenced by abundance variation. Recent empirical evidence available supports this assertion (Rezende et al. 2007; P. Jordano and J. Bascompte, personal observation).

Overall, we demonstrate that network patterns are determined by short-term variation in abundance and seasonal variation in resource-switching behavior. Nevertheless, acting at slower temporal rates of variation, the adaptive processes shaping foraging morphological traits also seem to play a very important role in defining global network architecture. Adaptive evolutionary processes acting on beak morphology and other traits would ultimately determine the ability of bird species to switch to fruits and the relative percentage of fruits in the diet for each species (Jordano 1987, Abzhanov et al. 
2004, Wu et al. 2004, Thompson 2005) and thus largely shape variation in degree (i.e., generalization level) across species. Therefore, adaptive processes acting on bird foraging traits possibly define the roles of bird generalist and specialist species and the specific locations within the whole network architecture (Stang et al. 2006). However, other variables, such as local abundance, may determine the short-term responses that result in varying degrees of interaction strength among species.

\section{ACKNOWLEDGMENTS}

Eloy Revilla, Daniel Sol, and Enrico Rezende provided advice with the phylogenetic and statistical analyses. This work was funded by grants REN2003-00273 and CGL2006-00373 from the Spanish Ministerio de Ciencia y Tecnología (MCyT). J. Carnicer was funded by MCyT AP2002-1762 research grant. J. Carnicer developed this work during a shortstance grant funded by the MCyT at NCEAS (University of California). C. J. Melián was supported by a Postdoctoral Fellowship at NCEAS, a Center funded by NSF (Grant DEB0553768), UCSB, and the State of California.

\section{Literature Cited}

Abrams, P. A. 2006. The effects of switching behavior on the evolutionary diversification of generalist consumers. American Naturalist 168:645-659.

Abzhanov, A., M. Protas, B. R. Grant, P. R. Grant, and C. J. Tabin. 2004. Bmp4 and morphological variation of beaks in Darwin's finches. Science 305:1462-1464.

Agrawal, A. A. 2001. Phenotypic plasticity in the interactions and evolution of species. Science 294:321-326.

Alarcón, R., N. M. Waser, and J. Ollerton. 2008. Year-to-year variation in the topology of a plant-pollinator interaction network. Oikos 117:1796-1807.

Allesina, S., and M. Pascual. 2008. Network structure, predator-prey modules, and stability in large food webs. Theoretical Ecology 1:55-64.

Bascompte, J., P. Jordano, C. J. Melián, and J. M. Olesen. 2003. The nested assembly of plant-animal mutualistic networks. Proceedings of the National Academy of Sciences (USA) 100:9383-9387.

Bascompte, J., P. Jordano, and J. M. Olesen. 2006. Asymmetric coevolutionary networks facilitate biodiversity maintenance. Science 312:431-434.

Beckerman, A. P., O. L. Petchey, and P. H. Warren. 2006. Foraging biology predicts food web complexity. Proceedings of the National Academy of Sciences (USA) 12:13745-13749.

Benkman, C. W. 1999. The selection mosaic and diversifying coevolution between crossbills and lodgepole pine. American Naturalist 153:S75-S91.

Berec, M., V. Krivan, and L. Berec. 2003. Are great tits (Parus major) really optimal foragers? Canadian Journal of Zoology 81:780-788

Berthold, P. 1976. The control and significance of animal and vegetable nutrition in omnivorous songbirds. Ardea 64:140154.

Björklund, M. 2006. Trait evolution, morphological integration and functional complexes. Acta Zoologica Sinica 52:494497.

Blomberg, S. P., T. J. Garland, and A. R. Ives. 2003. Testing for phylogenetic signal in comparative data: behavioral traits are more labile. Evolution 57:717-745.

Böhning-Gaese, K., and R. Oberrath. 1999. Phylogenetic effects on morphological, life-history, behavioral and ecological traits of birds. Evolutionary Ecology Research 1:347364.
Böhning-Gaese, K., and R. Oberrath. 2001. Which factors influence the abundance and range size of Central European birds? Avian Science 1:43-54.

Böhning-Gaese, K., M. D. Schuda, and A. J. Helbig. 2003. Weak phylogenetic effects on ecological niches of Sylvia warblers. Journal of Evolutionary Biology 16:956-965.

Brandes, U., and T. Erlebach. 2005. Network analysis. Methodological foundations. Springer-Verlag, Berlin, Germany.

Carnicer, J., P. A. Abrams, and P. Jordano. 2008. Switching behavior, coexistence and diversification: comparing community-wide evidence with theoretical predictions. Ecology Letters 11:802-808.

Cattin, M., L. Bersier, C. Banasek-Richter, R. Baltensperger, and J. Gabriel. 2004. Phylogenetic constraints and adaptation explain food-web structure. Nature 427:835-839.

Charnov, E. L. 1976. Optimal foraging: attack strategy of a mantid. American Naturalist 110:141-151.

Clauset, A., C. Moore, and M. E. J. Newman. 2008. Hierarchical structure and the prediction of missing links in networks. Nature 453:98-100.

Cofre, H. L., K. Böhning-Gaese, and P. A. Marquet. 2007. Rarity in Chilean forest birds: which ecological and lifehistory traits matter? Diversity and Distributions 13:203-212.

Cohen, J. E., F. Briand, and C. H. Newman. 1990. Community food webs: data and theory. Springer-Verlag, New York, New York, USA.

Coulson, T., T. G. Benton, P. Lundberg, S. R. X. Dall, and B. E. Kendall. 2006. Putting evolutionary biology back in the ecological theatre: a demographic framework mapping genes to communities. Evolutionary Ecology Research 8:11551171.

De Nooy, W., A. Mrvar, and V. Batajelj. 2005. Exploratory social network analysis with Pajek. Cambridge University Press, Cambridge, UK. 〈http://vlado.fmf.uni-lj.si/pub/ networks/pajek/>

Elton, C. 1927. Animal ecology. Sidgwick and Jackson, London, UK.

Emlen, J. T. 1981. Population densities of birds derived from transect counts. Auk 88:323-342.

Eveleigh, E. S., K. S. McKann, P. C. McCarthy, S. J. Pollock, C. J. Lucarotti, B. Morin, G. A. McDougall, D. B. Strongman, J. T. Huber, J. Umbanhowar, and L. D. B. Faria. 2007. Fluctuations in density of an outbreak species drive diversity cascades in food webs. Proceedings of the National Academy of Sciences (USA) 104:16977-16981.

Felsenstein, J. 1985. Phylogenies and the correlative method. American Naturalist 125:1-15.

Fitzpatrick, M. J., Y. Ben-Shahar, H. M. Smid, L. E. M. Vet, G. E. Robinson, and M. B. Sokolowski. 2005. Candidate genes for behavioral ecology. Trends in Ecology and Evolution 20:96-104.

Fryxell, J. M., and P. Lundberg. 1994. Diet choice and predator-prey dynamics. Evolutionary Ecology 8:407-421.

Fussman, G. F., M. Loreau, and P. A. Abrams. 2007. Ecoevolutionary dynamics of communities and ecosystems. Functional Ecology 21:465-477.

García, D., and R. Ortiz-Pulido. 2004. Patterns of resource tracking by avian frugivores at multiple spatial scales: two case studies on discordance among scales. Ecography 27:187196.

Gomulkiewicz, R., D. M. Drown, M. F. Dybdahl, W. Godsoe, K. M. Pepin, B. J. Ridenhour, C. I. Smith, and J. B. Poder. 2007. Dos and don'ts of testing the geographic mosaic theory of coevolution. Heredity 98:249-258.

Grant, P. R., and B. R. Grant. 2006. Evolution of character displacement in Darwin's finches. Science 313:224-226.

GraphPad Software. 2008. Prism, Version 5.0. GraphPad Software, San Diego, California, USA. 〈http://www. graphpad.com/prism/Prism.htm $\rangle$ 
Guimerà, R., and L. A. N. Amaral. 2005. Functional cartography of complex metabolic networks. Nature 433: 895-900.

Hairston, N. G., S. P. Ellner, M. A. Geber, T. Yoshida, and J. A. Fox. 2005. Rapid evolution and the convergence of ecological and evolutionary time. Ecology Letters 8:11141127.

Hastings, A. 2004. Transients: the key to long-term ecological understanding? Trends in Ecology and Evolution 19:39-45.

Hendry, A. P., P. Nosil, and L. H. Rieseberg. 2007. The speed of ecological speciation. Functional Ecology 21:455-464.

Herrera, C. M. 1984. A study of avian frugivores, birddispersed plants and their interaction in Mediterranean shrubland. Ecological Monographs 54:1-23.

Holt, R. D. 2002. Food webs in space: on the interplay of dynamic instability and spatial processes. Ecological Research 17:261-273.

Johnson, M. T. J., and J. R. Stinchcombe. 2007. An emerging synthesis between community ecology and evolutionary biology. Trends in Ecology and Evolution 22:250-256.

Jordano, P. 1984. Relaciones entre plantas y aves frugívoras en el matorral mediterráneo del sur de España. Dissertation. University of Sevilla, Sevilla, Spain.

Jordano, P. 1985. El ciclo anual de los paseriformes frugívoros en el matorral mediterráneo del sur de España: importancia de su invernada y variaciones interanuales. Ardeola 32:69-94.

Jordano, P. 1987a. Frugivory, external morphology and digestive system in Mediterranean sylviid warblers Sylvia spp. Ibis 129:175-189.

Jordano, P. 1987b. Patterns of mutualistic interactions in pollination and seed dispersal: connectance, dependence, asymmetries, and coevolution. American Naturalist 129:657-677.

Jordano, P. 1987c. Notas sobre la dieta no-insectívora de algunos Muscicapidae. Ardeola 34:89-98.

Jordano, P. 1994. Spatial and temporal variation in the avianfrugivore assemblage of Prunus mahaleb: patterns and consequences. Oikos 71:479-491.

Jordano, P., J. Bascompte, and J. M. Olesen. 2003. Invariant properties in coevolutionary networks of plant-animal interactions. Ecology Letters 6:69-81.

Jordano, P., J. Bascompte, and J. M. Olesen. 2006. The ecological consequences of complex topology and nested structure in pollination webs. Pages 173-199 in N. M Waser and J. Ollerton, editors. Specialization and generalization in plant-pollinator interactions. University of Chicago Press, Chicago, Illinois, USA.

Krivan, V. 1996. Optimal foraging and predator-prey dynamics. Theoretical Population Biology 49:265-290.

Lindemann, R. L. 1942. The trophic-dynamic aspect of ecology. Ecology 23:399-418.

Martins, E. P. 2004. COMPARE, version 4.6b. Computer programs for the statistical analysis of comparative data. Indiana University, Bloomington, Indiana. USA. 〈http:// compare.bio.indiana.edu $\rangle$

May, R. M. 1973. Stability and complexity in model ecosystems. Princeton University Press, Princeton, New Jersey, USA.

McCann, K. S. 2000. The diversity-stability debate. Nature 405:228-233.

McCann, K., A. Hastings, and G. R. Huxel. 1998. Weak trophic interactions and the balance of the nature. Nature 395:794-797.

McCann, K., J. B. Rasmussen, and J. Umbanhowar. 2005. The dynamics of spatially coupled food webs. Ecology Letters 8: 513-523.

Midford, P. E., T. Garland, and W. Maddison. 2002. PDAP:PDTREE package for Mesquite, version 1.00. 〈http://mesquiteproject.org/pdap_mesquite/>

Mönkkönen, M., and J. T. Forsman. 2002. Heterospecific attraction among forest birds: a review. Ornithological Science 1:41-51.
Murdoch, W. W. 1969. Switching in general predators: experiments on predator specificity and stability of prey populations. Ecological Monographs 39:335-354.

Nagy, K. A. 1987. Field metabolic rate and food requirement scaling in mammals and birds. Ecological Monographs 57: 111-128.

Neutel, A., J. A. P. Heesterbeek, J. van de Koppel, G. Hoenderboom, A. Vos, C. Kaldeway, F. Berendse, and P. C. de Ruiter. 2007. Reconciling complexity with stability in naturally assembling food webs. Nature 449:599-602.

Olesen, J. M., J. Bascompte, Y. Dupont, and P. Jordano. 2007. The modularity of pollination networks. Proceedings of the National Academy of Sciences (USA) 104:19891-19896.

Olesen, J. M., J. Bascompte, H. Elberling, and P. Jordano. 2008. Temporal dynamics in a pollination network. Ecology 89:1573-1582.

Owen-Smith, N., and M. G. L. Mills. 2008. Shifting prey selection generates contrasting herbivore dynamics within a large-mammal predator-prey web. Ecology 89:1120-1133.

Paine, R. T. 1992. Food-web analysis through field measurement of per capita interaction strength. Nature 355:73-75.

Phillimore, A. B., R. P. Freckleton, C. D. L. Orme, and I. P. F. Owens. 2006. Ecology predicts large-scale patterns of phylogenetic diversification in birds. American Naturalist 168:220-229.

Pimm, S. L. 1982. Food webs. Chapman and Hall, New York, New York, USA.

Podos, J. 2001. Correlated evolution of morphology and vocal signal structure in Darwin's finches. Nature 409:185-188.

Polis, G. A., and K. O. Winemiller. 1996. Food webs: integration of patterns and dynamics. Chapman and Hall, London, UK.

Price, T. D., A. Qvarnström, and D. E. Irwin. 2003. The role of phenotypic plasticity in driving genetic evolution. Proceedings of the Royal Society B 270:1433-1440.

Rey, P. J. 1995. Spatio-temporal variation in fruit and frugivorous bird abundance in olive orchards. Ecology 76: $1625-1635$.

Rezende, E. L., J. E. Lavabre, P. R. Guimaraes, P. Jordano, and J. Bascompte. 2007. Non-random coextinctions in phylogenetically structured networks. Nature 448:925-928.

Rooney, N., K. McCann, G. Gellner, and J. C. Moore. 2006. Structural asymmetry and the stability of diverse food webs. Nature 442:265-269.

Rooney, N., K. S. McCann, and J. C. Moore. 2008. A landscape theory for food web architecture. Ecology Letters 11:867-881.

Sabo, J. L., B. E. Beisner, E. L. Berlow, K. Cuddington, A. Hastings, M. Koen-Alonso, K. McCann, C. Melian, and J. Moore. 2005. Population dynamics of food web properties with minimal detail and resolution. Pages 437-450 in P. C. de Ruiter, V. Wolters, and J. C. Moore, editors. Dynamic food webs: multispecies assemblages, ecosystem development and environmental change. Academic Press, New York, New York, USA.

SAS Institute. 1989-2002. JMP. Version 5.0. SAS Institute, Cary, North Carolina, USA.

SAS Institute. 2008. GLIMMIX procedure of SAS 9.1.3. SAS Institute, Cary, North Carolina, USA.

Stang, M., P. G. L. Klinkhamer, and E. van der Meijden. 2006. Asymmetric specialization and extinction risk in plant-flower visitor webs: a matter of morphology or abundance? Oecologia 140:491-492.

Stephens, D. W., and J. R. Krebs. 1986. Foraging theory. Princeton University Press, Princeton, New Jersey, USA.

Tellería, J. L., and R. Carbonell. 1999. Morphometric variation of five Iberian blackap Sylvia atricapilla populations. Journal of Avian Biology 30:63-71.

Tellería, J. L., A. Ramírez, and J. Pérez-Tris. 2008. Fruit tracking between sites and years by birds in Mediterranean wintering grounds. Ecography 31:381-388. 
Thompson, J. N. 2005. The geographical mosaic of coevolution. University of Chicago Press, Chicago, Illinois, USA.

Van Baalen, M., V. Krivan, P. C. J. van Rijn, and M. Sabelis. 2001. Alternative food, switching predators and the persistence of predator-prey systems. American Naturalist 157: $512-524$.

Vázquez, D. P., and M. A. Aizen. 2004. Asymmetric specialization: a pervasive feature of plant-pollinator interactions. Ecology 85:1251-1257.

Vázquez, D. P., C. J. Melián, N. M. Williams, N. Blüthgen, B. R. Krasnov, and R. Poulin. 2007. Species abundance and asymmetric strength in ecological networks. Oikos 116:11201127.

Vázquez, D. P., W. F. Morris, and P. Jordano. 2005. Interaction frequency as a surrogate for the total effect of animal mutualists on plants. Ecology Letters 8:1088-1094.
Wcislo, W. T. 1989. Behavioral environments and evolutionary change. Annual Review of Ecology and Systematics 20:137169.

Winemiller, K. O. 1990. Spatial and temporal variation in tropical fish trophic networks. Ecological Monographs 60: 331-367.

Wolfinger, R., and M. O'Connell. 1993. Generalized linear mixed models: a pseudo-likelihood approach. Journal of Statistical Computation and Simulation 48:233-243.

Wu, P., J. Ting-Xin, S. Suksaweang, R. B. Widelitz, and C. Chuong. 2004. Molecular shaping of the beak. Science 305: 1465-1466.

Yang, L. H., J. L. Bastow, K. O. Spence, and A. N. Wright. 2008. What can we learn from resource pulses? Ecology 89: 621-634.

\section{APPENDIX A}

Variation in the number of interactions observed at different timescale resolutions (Ecological Archives E090-135-A1).

\section{APPENDIX B}

Switching behavior classification (Ecological Archives E090-135-A2).

\section{APPENDIX C}

Temporal changes in network structure during 1981-1983 (Ecological Archives E090-135-A3).

\section{APPENDIX D}

Test effects for nine morphological variables predicting the variation in the proportion of fruits in the diet (Ecological Archives E090-135-A4).

\section{APPENDIX E}

Values and significance of the statistic $K$ for the variables under study (Ecological Archives E090-135-A5).

\section{SUPPLEMENT}

MATLAB code used in the calculation of asymmetry values (Ecological Archives E090-135-S1). 


\section{Ecological Archives E090-135-A1}

Jofre Carnicer, Pedro Jordano, and Carlos J. Melián. 2009. The temporal dynamics of resource use by frugivorous birds: a network approach. Ecology 90:1958-1970.

Appendix A. Variation of the number of interactions observed at different time-scale resolutions.

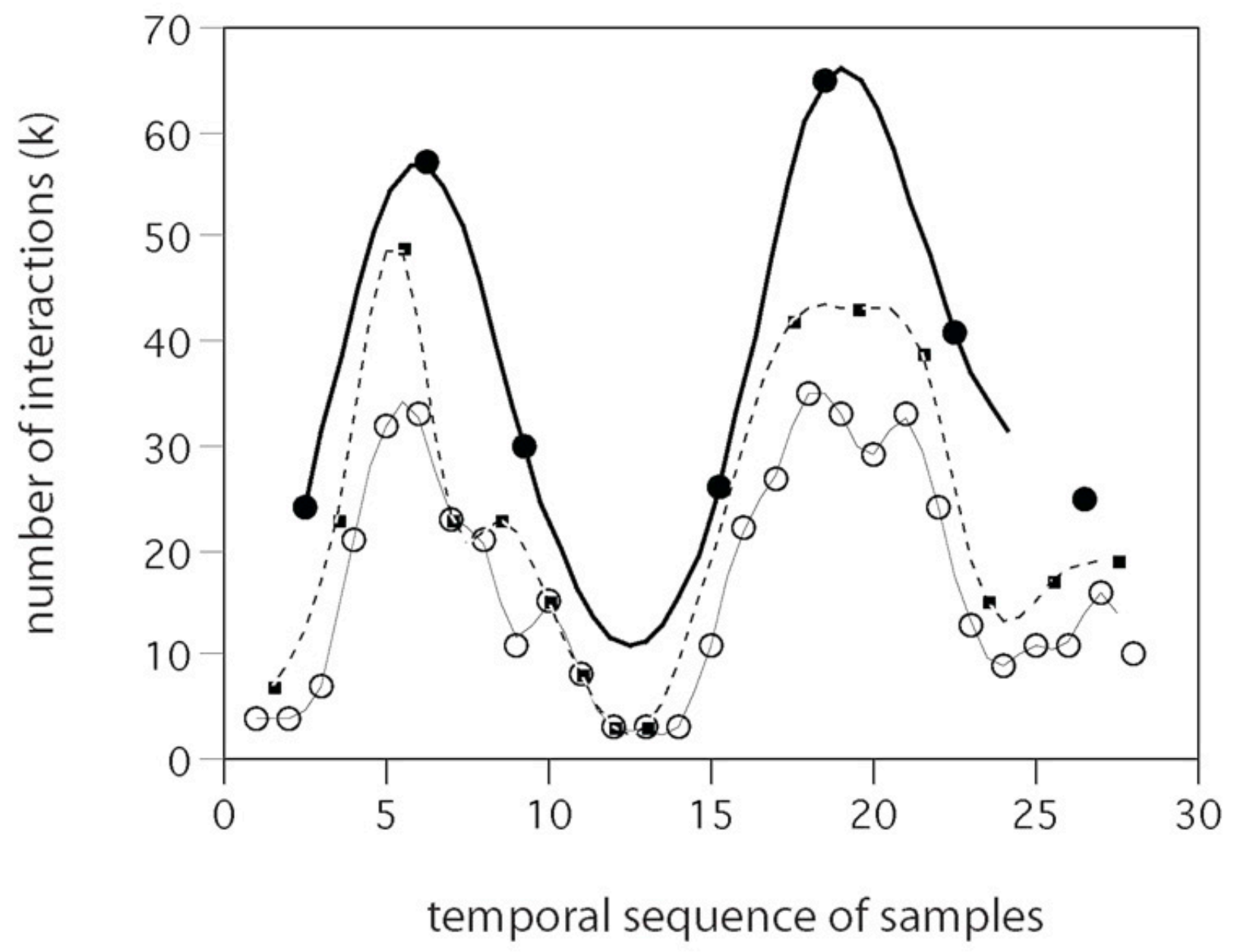

FIG. A1. Variation in the total number of interactions observed at three different scales of temporal resolution (15 days, white dots, thin black line; one month, black squares, dashed line; two months, black dots, wide black line) during the whole study period (temporal sequence of samples). Note that the space between adjacent curves is proportional to the temporal turnover in species interactions. These results suggest a high turnover in the type and number of interactions, specially on the fruiting peak crests.

[Back to E090-135] 


\section{Ecological Archives E090-135-A2}

Jofre Carnicer, Pedro Jordano, and Carlos J. Melián. 2009. The temporal dynamics of resource use by frugivorous birds: a network approach. Ecology 90:1958-1970.

Appendix B. Switching behavior classification.

TABLE B1. Community species. $\mathrm{S}=$ Fast switchers were characterized with low switching delay values $(<0.4)$ and fast response curves (Appendix C) ; $\mathrm{s}=$ Switchers with fast response curves for which a statistical fit of sigmoid curves was not allowed due to small sample size; $\mathrm{S}^{*}=$ species that showed delayed switching behavior (switching delay $>0.4$ ); $\mathrm{I}=$ species that consumed mostly invertebrates. $U=$ unclassified species due to small sample size. ${ }^{* *}$ Significant sigmoid fit with $P<0.01$.

\begin{tabular}{|c|c|c|c|c|}
\hline GROUP & $\begin{array}{l}\text { COD } \\
\mathrm{E}\end{array}$ & Species & CODE & $\begin{array}{l}\text { Switching } \\
\text { Delay }\end{array}$ \\
\hline \multirow{10}{*}{$\begin{array}{l}\text { Fast } \\
\text { switchers }\end{array}$} & $\mathrm{S}$ & Sylvia cantillans & SCAN & $0.189 * *$ \\
\hline & $\mathrm{S}$ & Sylvia borin & SBOR & $0.191 * *$ \\
\hline & $\mathrm{S}$ & Erithacus rubecula & ERUB & $0.193 * *$ \\
\hline & $\mathrm{S}$ & Sylvia atricapilla & SATR & $0.218 * *$ \\
\hline & $\mathrm{S}$ & Sylvia communis & SCOM & $0.231 * *$ \\
\hline & $\mathrm{S}$ & Sylvia melanocephala & SMEL & $0.232 * *$ \\
\hline & $\mathrm{S}$ & Turdus merula & TMER & $0.264 * *$ \\
\hline & $\mathrm{s}$ & Sylvia hortensis & SHOR & - \\
\hline & $\mathrm{s}$ & Turdus philomelos & TPHI & - \\
\hline & $\mathrm{s}$ & Phoenicurus phoenicurus & PPHO & - \\
\hline \multirow{4}{*}{$\begin{array}{l}\text { Delayed } \\
\text { switchers }\end{array}$} & S* & Luscinia megarhynchos & LMEG & $0.467 * *$ \\
\hline & S* & Sylvia undata & SUND & $0.540 * *$ \\
\hline & $\mathrm{S}^{*}$ & Muscicapa striata & MSTR & $0.600 * *$ \\
\hline & S* & Ficedula hypoleuca & FHYP & $1.322 * *$ \\
\hline \multirow[t]{5}{*}{ Specialists } & I & Hippolais polyglotta & HPOL & - \\
\hline & $\mathrm{I}$ & Phylloscopus collybita & PCOL & - \\
\hline & I & Phylloscopus trochilus & PTRO & - \\
\hline & I & Phylloscopus bonelli & PBON & - \\
\hline & I & Regulus ignicapillus & RIGN & - \\
\hline \multirow[t]{6}{*}{ Unclassified } & $\mathrm{U}$ & Parus major & PMAJ & - \\
\hline & $\mathrm{U}$ & Parus caeruleus & PCAE & - \\
\hline & $\mathrm{U}$ & Parus cristatus & PCRI & - \\
\hline & $\mathrm{U}$ & Saxicola torquata & STOR & - \\
\hline & $\mathrm{U}$ & Turdus iliacus & TILI & - \\
\hline & $\mathrm{U}$ & Phoenicurus ochruros & $\mathrm{POCH}$ & - \\
\hline
\end{tabular}


Ecological Archives E090-135-A3

Jofre Carnicer, Pedro Jordano, and Carlos J. Melián. 2009. The temporal dynamics of resource use by frugivorous birds: a network approach. Ecology 90:1958-1970.

Appendix C. Temporal changes in network structure in 1981-1983.

\section{1-1982}

$1-15$ July

16-31 August
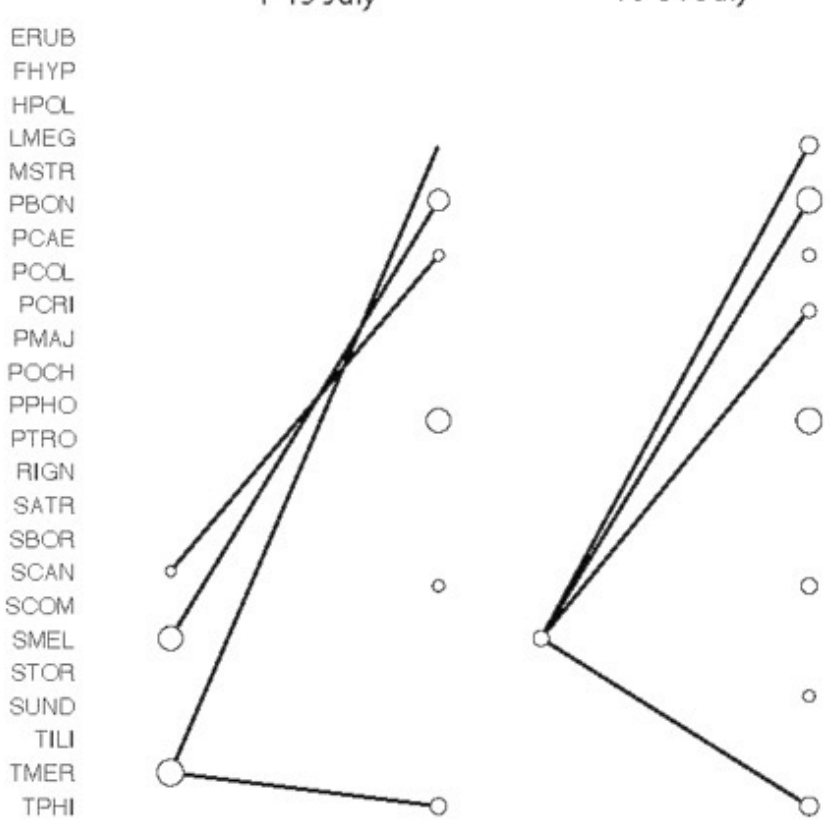

1-15 September

ERUB

FHYP

$\mathrm{HPOL}$

LMEG

MSTR

PBON

PCAE

$\mathrm{PCOL}$

PCRI

PMAJ

$\mathrm{POCH}$

$\mathrm{PPHO}$

PTRO

RIGN

SATR

SBOR

SCAN

SCOM

SMEL

STOR

SUND

TILI

TMER

TPHI
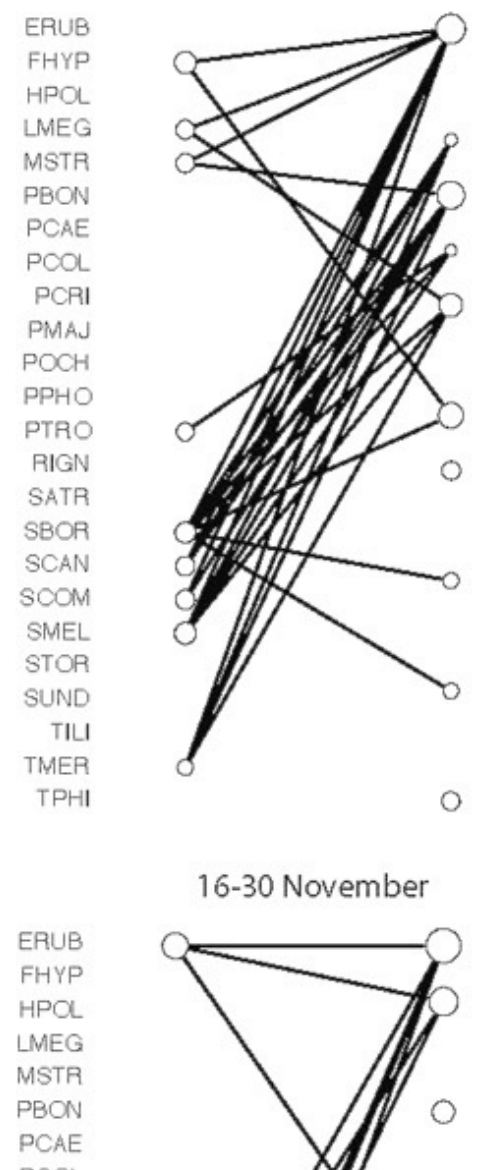

16-30 September

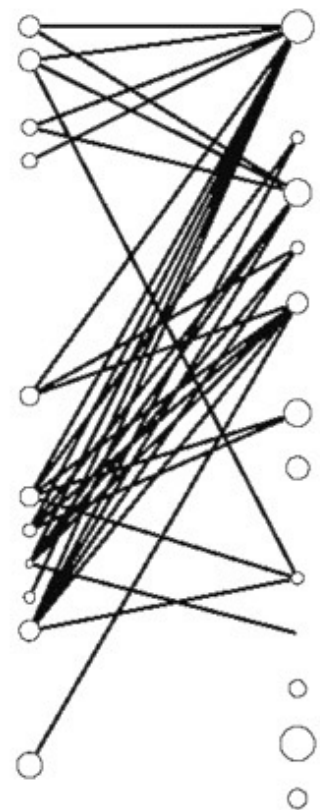

16-31 December

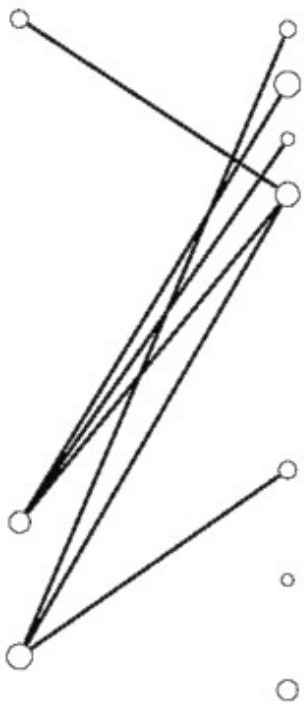

1-15 October
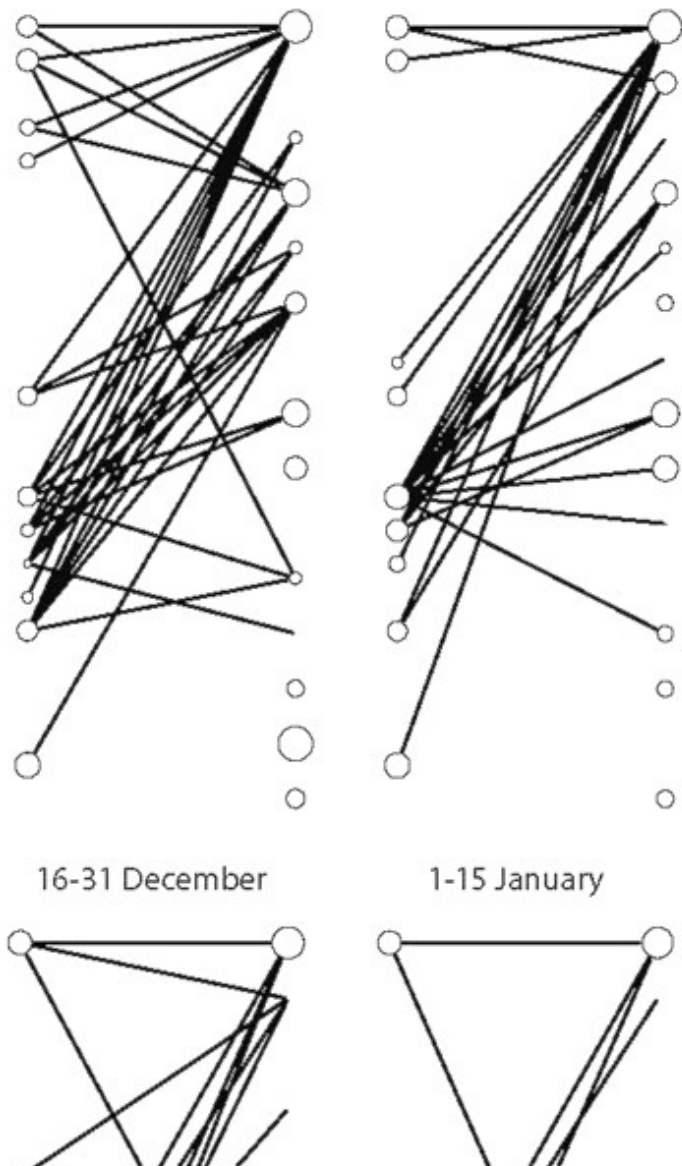

1-15 January

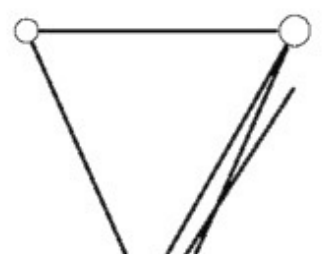

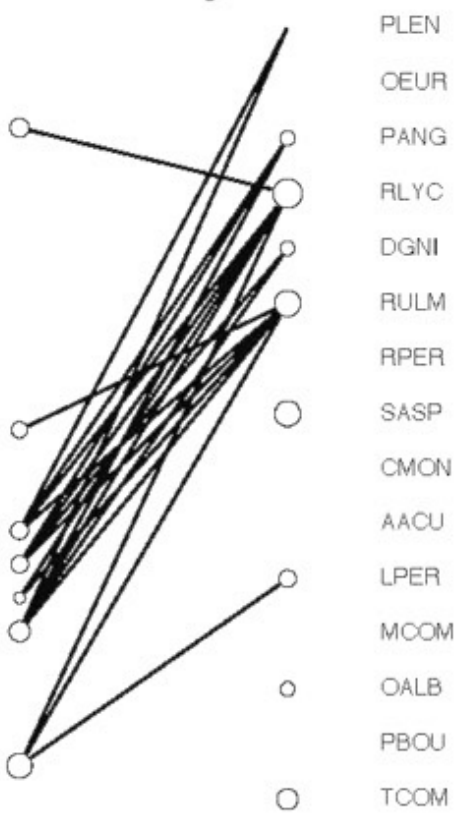

1-15 November

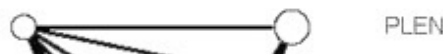

OEUR

PANG

RLYC

DGNI

RULM

RPER

SASP

CMON

AACU

LPER

MCOM

OALB

$\mathrm{PBOU}$

TCOM

16-28 February

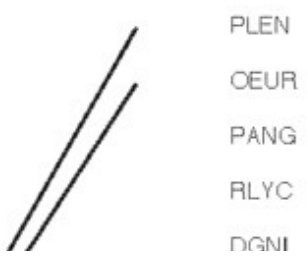



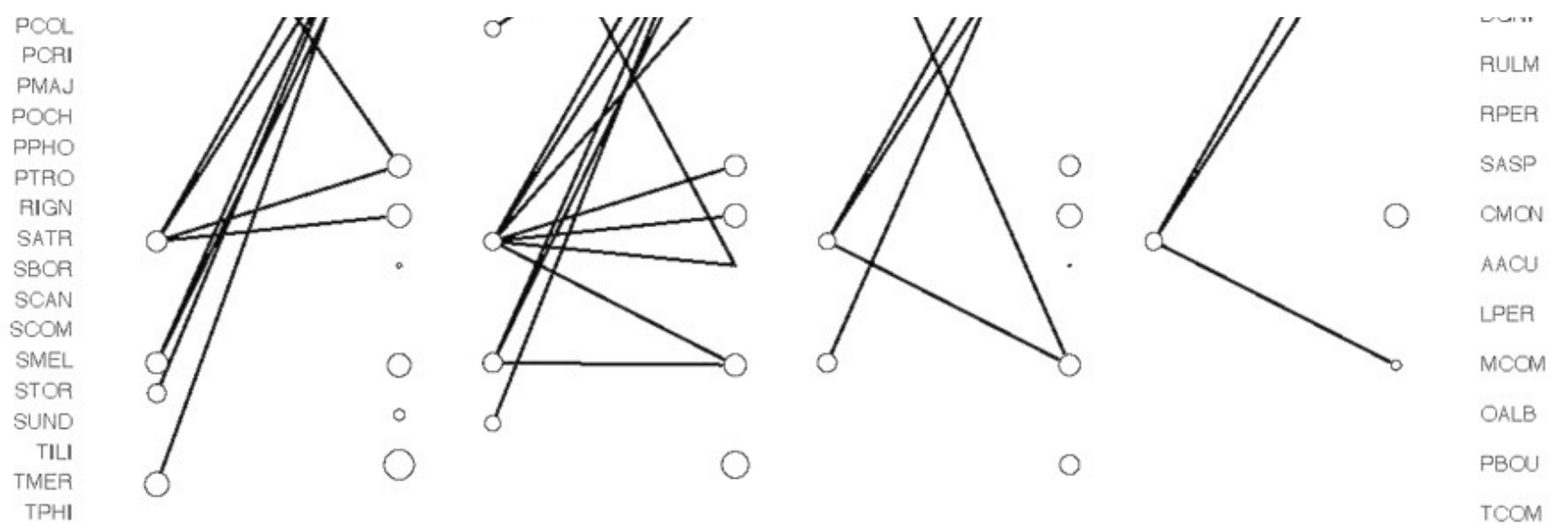

\section{2-1983}
1-15 July
16-31 July
16-31 August
1-15 September
16-30 September
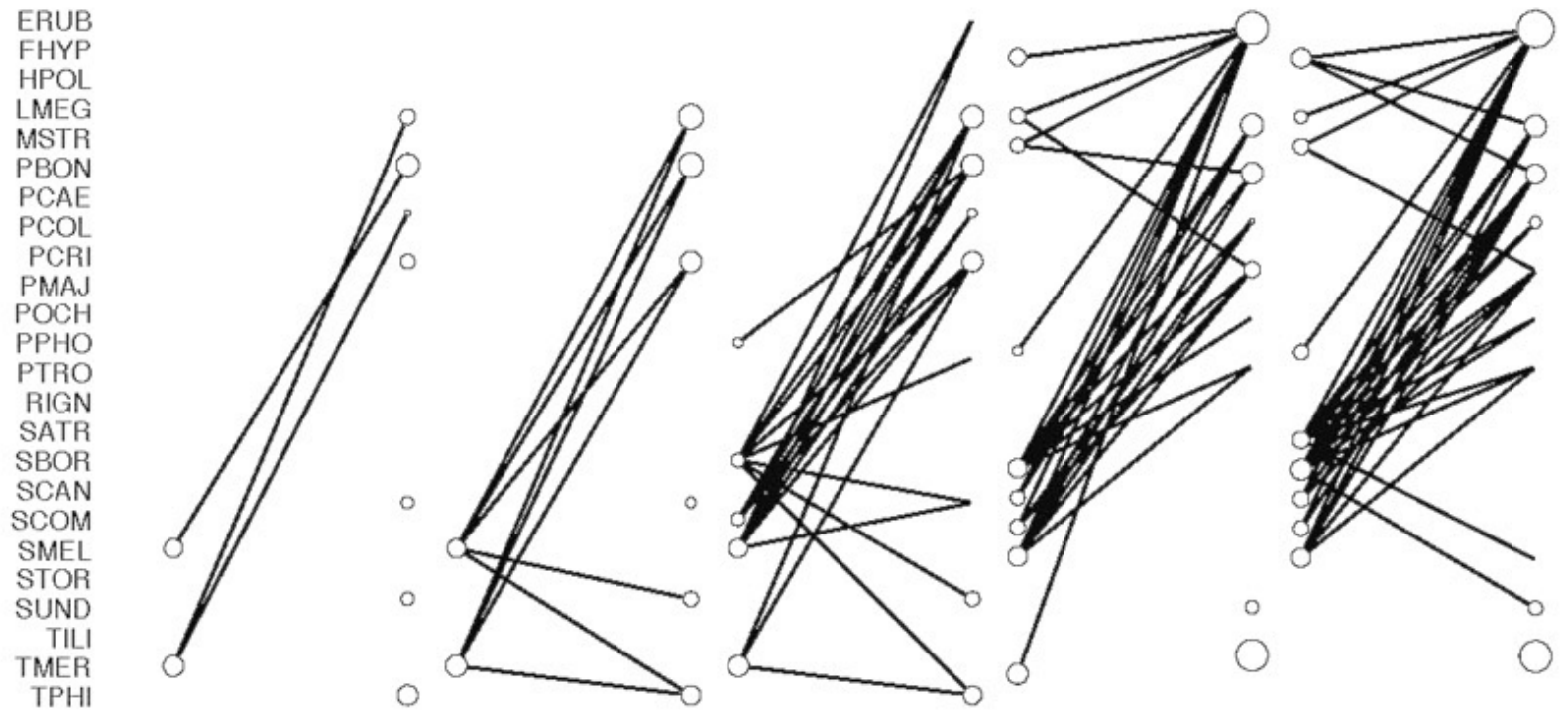

PLEN

OEUR

PANG

RLYC

DGNI

RULM

RPER

SASP

CMON

AACU

LPER

MCOM

OALB

PBOU

TCOM

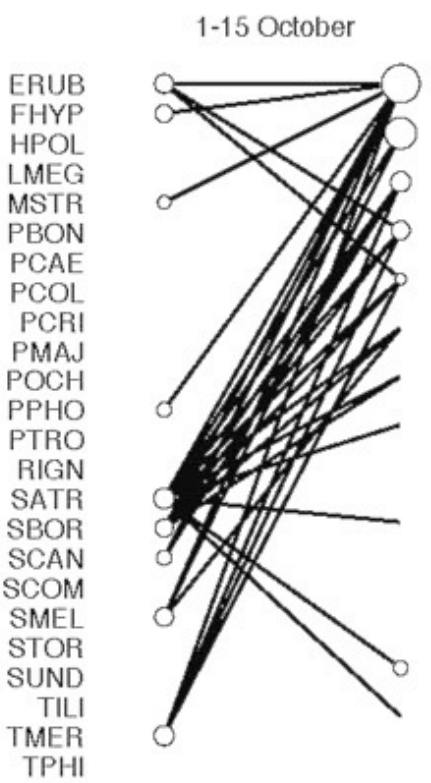

16-31 October

16-30 November

1-15 December
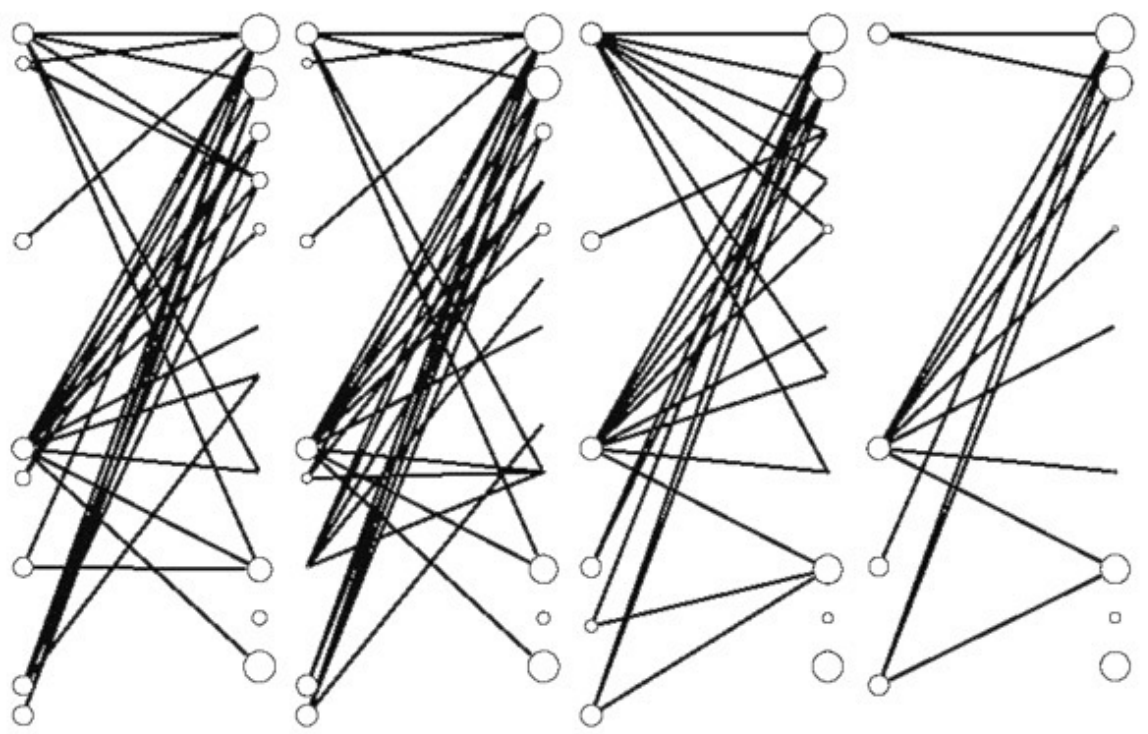

PLEN

OEUR

PANG

RLYC

DGNI

RULM

RPER

SASP

CMON

AACU

LPER

MCOM

OALB

PBOU

TCOM

16-31 December

1-15 January

16-31 January

1-15 February

16-28 February

DI EN 

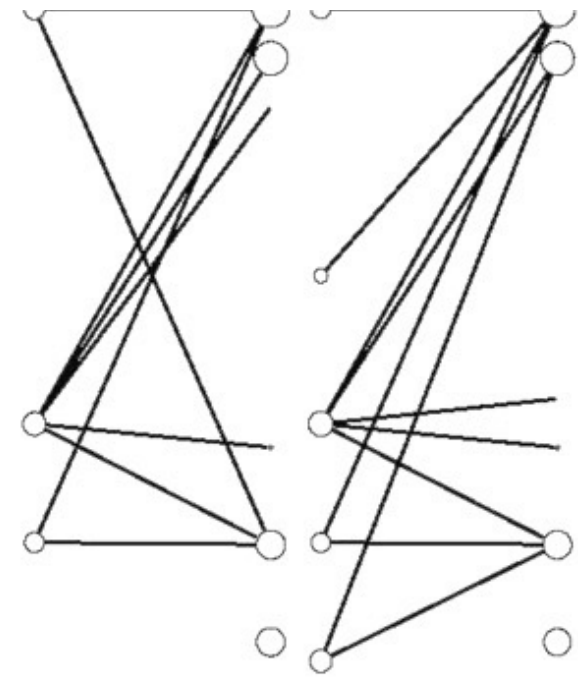

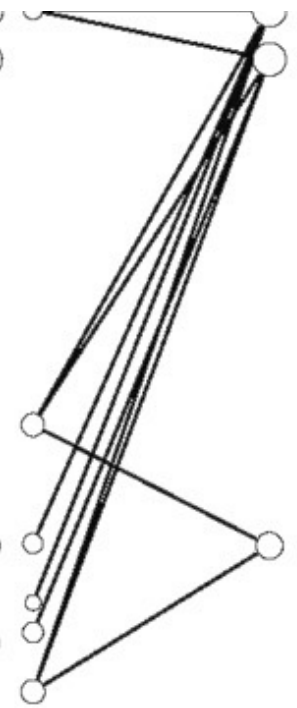

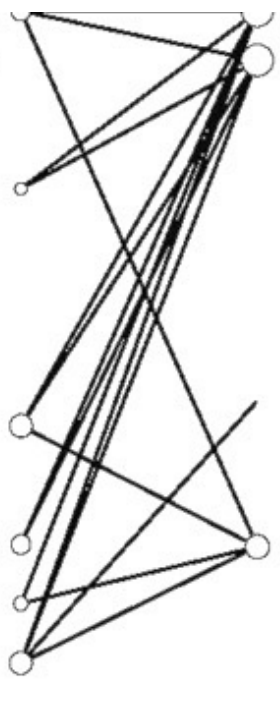

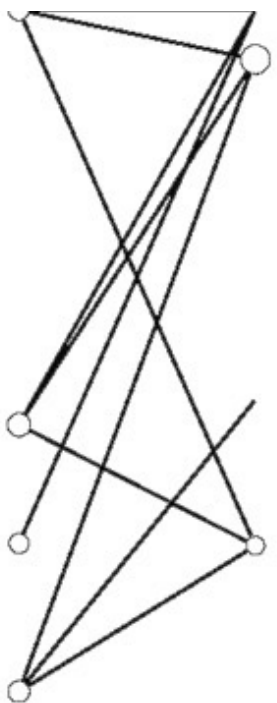

OEUR

PANG

RLYC

DGNI

RULM

RPER

SASP

CMON

AACU

LPER

MCOM

OALB

PBOU

TCOM

FIG. C1. Temporal changes in network structure in 1981-1983. For illustrative purposes, bird nodes were scaled to daily energetic requirement in a logarithmic scale (kJ/day) using scaling regression techniques (Nagy 1987). Plant nodes were scaled to the logarithm of fruit energy production (kJ/15 days) using specific estimates of fruit energy content ( $\mathrm{kJ} / \mathrm{species}$ of fruit) and fruit crop estimates (Jordano 1984). Left-hand column refers to bird species and right-hand column refers to plants. A description of species codes is provided in Appendix B.

\section{LITERATURE CITED}

Nagy, K. A. 1987. Field metabolic rate and food requirement scaling in mammals and birds. Ecological Monographs 57:111-128.

[Back to E090-135] 


\section{Ecological Archives E090-135-A4}

Jofre Carnicer, Pedro Jordano, and Carlos J. Melián. 2009. The temporal dynamics of resource use by frugivorous birds: a network approach. Ecology 90:1958-1970.

Appendix D (Table D1). Test effects for nine morphological variables predicting the variation in the proportion of fruits in the diet. $* * * * P<0.0001$.

\begin{tabular}{|c|c|c|c|c|}
\hline Dependent & \multicolumn{4}{|c|}{$\% R_{1}$, percentage of fruits in the diet } \\
\hline$R^{2}$ adj. & \multicolumn{4}{|c|}{ 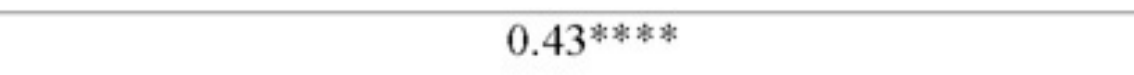 } \\
\hline Effect & SS & $F$ & $P$ & Sign \\
\hline Body mass & 6314.42 & 7.12 & 0.0087 & + \\
\hline Wing length & 8646.83 & 9.75 & 0.0023 & - \\
\hline Tail length & 4846.22 & 5.46 & 0.0210 & + \\
\hline Tarsus length & 12.66 & 0.014 & 0.9050 & + \\
\hline Culmen length & 9782.02 & 11.028 & 0.0012 & - \\
\hline Culmen length & 127.77 & 0.144 & 0.7049 & + \\
\hline Wide & 11.70 & 0.013 & 0.9088 & + \\
\hline Height & 139.48 & 0.157 & 0.6924 & - \\
\hline Gape width & 14401.91 & 16.23 & 0.0001 & + \\
\hline
\end{tabular}

[Back to E090-135] 


\section{Ecological Archives E090-135-A5}

Jofre Carnicer, Pedro Jordano, and Carlos J. Melián. 2009. The temporal dynamics of resource use by frugivorous birds: a network approach. Ecology 90:1958-1970.

Appendix E (TableE1). Values and significance of the statistic $K$ for the variables under study. 


\begin{tabular}{|c|c|c|}
\hline Variable & $K$ & $P$ \\
\hline \multicolumn{3}{|l|}{ Network } \\
\hline Degree & 0.929 & 0.005 \\
\hline Interaction Strength (IS) & 0.993 & 0.023 \\
\hline Maximum IS & 0.7 & 0.019 \\
\hline Minimum IS & 0.51 & $\mathrm{~ns}(0.081)$ \\
\hline Asymmetry & 0.681 & 0.01 \\
\hline Core & 0.62 & 0.027 \\
\hline Centrality & 0.57 & $\mathrm{~ns}(0.076)$ \\
\hline \multicolumn{3}{|l|}{ Abundance \& Behavior } \\
\hline Bird abundance & 0.330 & $\mathrm{~ns}(0.523)$ \\
\hline Mean percentage of fruits & 0.743 & 0.003 \\
\hline \multicolumn{3}{|l|}{ Morphological } \\
\hline Gape width & 1.850 & $<0.001$ \\
\hline Body size & 2.171 & $<0.001$ \\
\hline Intestine length & 1.52 & $<0.001$ \\
\hline Culmen height & 1.71 & $<0.001$ \\
\hline Wing length & 1.61 & $<0.001$ \\
\hline Tail length & 0.87 & $<0.001$ \\
\hline Tarsus length & 1.02 & $<0.001$ \\
\hline Culmen length 1 (skull base) & 1.04 & $<0.001$ \\
\hline Culmen length 2 (exposed) & 1.06 & 0.002 \\
\hline
\end{tabular}

[Back to E090-135] 
Jofre Carnicer, Pedro Jordano, and Carlos J. Melián. 2009. The temporal dynamics of resource use by frugivorous birds: a network approach. Ecology 90:1958-1970.

\section{Supplement}

MATLAB code used in the calculation of asymmetry values. Ecological Archives E090-135-S1.

\section{Copyright}

\section{$\underline{\text { Authors }}$ \\ File list (downloads) \\ Description}

\section{Author(s)}

Carlos J. Melian

National Center for Ecological Analysis and Synthesis (NCEAS)

Unibversity of California Santa Barbara (UCSB)

735 State Street, Suite 300

Santa Barbara, CA 93101 USA

E-mail: $\underline{\text { melian@nceas.ucsb.edu }}$

\section{File list}

Asymmetry.m -- main script

corr.m -- supplementary script

intimp.m -- supplementary script

quant2bin.m -- supplementary script

soertmatr.m -- supplementary script

\section{Description}

This Supplement contains a Matlab script used to calculate asymmetry values. Asymmetry.m needs four supplementary scripts ( corr.m, intimp.m, quant2bin.m, soertmatr.m).

As ymmetry.m generates the following outputs: total degree each row (1st column); frequency of interactions each row (2nd column); sum dependences each row (3rd column); asymmetry value for each row (4th column). Finally, it gives the correlation values between abundance and asymmetry. 


\section{LITERATURE CITED}

Vazquez, D. P., C. J. Melian, N. M. Williams, N. Bluthgen, B. R. Krasnov, and R. Poulin. 2007. Species abundance and asymmetric interaction strength in ecological networks. Oikos 116:1120-1127. 